Documenta \& Instrumenta

ISSN-e: 1697-3798

http://dx.doi.org/10.5209/rev_DOCU.2018.v16.60230

\title{
Contratos de impresión de libros con los tipógrafos extranjeros en Sa- lamanca en el siglo XVI ${ }^{1}$
}

\author{
Francisco Javier Lorenzo Pinar $^{2}$
}

Recibido: 21 de abril de 2017 / Aceptado: 10 de mayo de 2018

Resumen. El presente artículo trata de abordar las características, las posibles aportaciones y las carencias de los contratos de impresión para el estudio del mundo del libro en Salamanca, uno de los principales centros impresores españoles en el Quinientos. Este tipo de fuentes documentales aportan múltiples datos en su parte dispositiva - sobre financiación, tipos de letra y papel, tintas, encuadernaciones, etc.- - indispensables para el conocimiento de la edición libraría. Para lograr este propósito hemos utilizado la totalidad de las escrituras conservadas en los protocolos notariales para el siglo XVI firmadas por los impresores extranjeros de la urbe salmantina, principales editores de ella.

Palabras clave. Contratos; libros; imprenta; Salamanca; siglo XVI.

\section{[en] Contracts for printing books with the foreigners printers in Salamanca in Sixteenth Century}

\begin{abstract}
The present article tries to study the characteristics, the possible contributions and deficiencies of the printing contracts to study the book world in Salamanca, one of the main Spanish printer centres in the Sixteenth Century and of great demand of books becouse there were working many teachers and students in the city. This kind of documental source brings many dispositions about financing, types of letters and paper, inks, bindings, etc., essential to know the book editions. To obtain this objective we have used all the contracts preserved in the notarial records during this period, signed by the foreigners living in Salamanca, a collective that operated as the principal publisher of the city.
\end{abstract}

Keywords. Contracts; books; printing; Salamanca; Sixteenth Century.

Sumario. 1. Introducción. 2. Las condiciones contractuales. 3. Consideraciones finales. 4. Anexo.

Cómo citar: F. J. Lorenzo Pinar, "Contratos de impresión de libros con los tipógrafos extranjeros en Salamanca en el siglo XVI”, Documenta \& Instrumenta, 16 (2018), pp. 91-114.

1 Este trabajo ha sido desarrollado dentro del Proyecto de Investigación financiado por el Ministerio de Economía, Industria y Competitividad, con referencia HAR2017-84226-C6-4-P, titulado "Familias, cultura material, apariencia social y civilización. Identidades y representaciones en el interior peninsular (1500-1850)".

2 Universidad de Salamanca, IEMYR (España)

E-mail: lopinar@usal.es 


\section{Introducción}

La comercialización e impresión del libro en Salamanca ha sido objeto de atención de diferentes estudios a los que aludiremos a lo largo de este trabajo. El tema ha suscitado interés sobre todo si tenemos en cuenta que Salamanca contó con una de las imprentas más activas a lo largo del Quinientos. La ubicación en la urbe de la institución universitaria con mayor número de estudiantes durante esta centuria en toda monarquía hispana la convirtió en un potencial foco de transacciones ${ }^{3}$, tanto de mercaderes nacionales como de extranjeros ${ }^{4}$. La ciudad contaba además con numerosos monasterios y colegios seculares y regulares que actuaban como potenciales clientes de libreros e impresores ${ }^{5}$. También su cercanía con Medina del Campo - lugar de celebración de ferias, de importación de libros y de edición de los mismos - impulsó el intercambio de la mercancía libraría ${ }^{6}$. Las publicaciones de Lorenzo Ruiz Fidalgo, en donde se efectúa una relación de más de millar y medio de ediciones de obras impresas en Salamanca a lo largo del siglo XVI, constituyen el argumento probatorio más contundente a favor de estas afirmaciones ${ }^{7}$. Anastasio Rojo Vega, igualmente, califica a Salamanca como el mayor núcleo de consumo del libro de la Corona española y uno de los principales centros de esta mercancía, junto con la citada Medina del Campo, puerta de acceso a los libros impresos en Europa ${ }^{8}$.

Luisa Cuesta Gutiérrez ha resaltado, así mismo, el papel que jugaron los alemanes en los orígenes de la imprenta salmantina y la labor desarrollada por italianos,

3 Aunque en otros lugares hubo una coincidencia entre la llegada de la imprenta y el afianzamiento de una universidad — caso de Baeza_- parece que esta no tuvo el impacto que la salmantina en la tipografía. En los Países Bajos también encontramos localizaciones de imprentas por el atractivo que suponía una universidad, caso de Lovaina, donde profesores y estudiantes, antes del año 1500, constituyeron el primer grupo de clientes. Véase, P. M. CÁTEDRA, Imprenta y lecturas en la Baeza del siglo XVI, Salamanca, 2001, pp. 16-17; Hubert MEEUS, "Printing in the sadow of a Metropolis", en B. REAL COSTAS, Print Culture and Peripheries in Early Modern Europe. A contribution to the History of Printing and the Book Trade in Small European and Spanish Cities, Leiden-Boston, 2013, pp. 156-157.

4 Natalia Maillard subraya la abundancia de libreros e impresores extranjeros en Medina del Campo y Salamanca frente a otras ciudades como Sevilla donde predominaron los castellanos. El papel de los impresores extranjeros en la ciudad salmantina también ha sido resaltado por otros trabajos. Véase, N. MAILLARD ÁLVAREZ, "El mercado del libro en Sevilla con Felipe II", en P. M. CÁTEDRA y Ma . L. LÓPEZ-VIDRIERO, La memoria de los libros. Estudios sobre la historia del escrito y de la lectura en Europa y América, II. Salamanca, 2004, pp. 319-326; H. ESCOLAR (dir.), Historia ilustrada del libro español. De los incunables al siglo XVIII, Madrid, 1994, p. 28.

5 En Galicia las imprentas tuvieron casi como únicas sedes las ciudades episcopales en el siglo XVI, dato indicativo del carácter promotor y clientelar desempeñado por el clero. O. REY CASTELAO, Libros y lectura en Galicia. Siglos XVI-XIX, Santiago de Compostela, 2003, p. 93.

6 L. CUESTA GUTIÉRREZ, La imprenta en Salamanca. Avance al estudio de la tipografía Salamantina (1480-1944), Salamanca, 1960, pp. 21-22; M. PEÑA DÍAZ, "El comercio, la circulación y la geografía del libro", en V. INFANTES, F. LÓPEZ y J.-F. BOTREL, Historia de la edición y de la lectura en España. 14721914, Madrid, 2003, pp. 85-91.

7 L. RUIZ FIDALGO, La imprenta en Salamanca: (1501-1560). Madrid: Arco-Libros, 1994; La imprenta en Salamanca: (1501-1560): segundos addenda et corrigenda, II, Madrid, 1998, pp. 391-410.

8 A. ROJO VEGA, "Medina del Campo: Centro de distribución de libros", en VV. AA., Libros y ferias. El primer comercio del libro impreso. V centenario de la imprenta en Medina del Campo. 1511-2011. Valladolid, 2011, p. 85. 
franceses o flamencos a lo largo del siglo XVI ${ }^{9}$. Las perspectivas de negocio a las que hemos aludido condujeron a la formación en la década de los años 30 de esta centuria de una compañía de libreros de corta vida - la cual ha sido analizada por Vicente Bécares y Marta de la Mano ${ }^{10}$ - en la que participaron mercaderes nacionales y extranjeros, tanto residentes en Salamanca (franceses, flamencos e italianos) como en Medina del Campo (alemanes) para importar libros que demandaba el mercado y que no eran suministrados por la industria nacional ${ }^{11}$. Posteriormente se formarían otras sociedades de menor entidad, algunas de las cuales llegaron a tener una larga existencia, caso de la de Juan de Junta, florentino y Alejandro de Cánova, italiano, entre otras ${ }^{12}$.

El papel de la imprenta salmantina que hemos subrayado nos haría pensar, a priori, en una proliferación de contratos para imprimir libros conservados en los protocolos notariales de la ciudad; sin embargo, como veremos, estas expectativas se han visto frustradas. Al no preservarse la documentación particular de los libreros - memorias, correspondencia, libros de cuenta, etc.- donde quedaban reflejados los aspectos relativos a sus negocios, los contratos que han sobrevivido constituyen una fuente de información si no única, sí imprescindible para el conocimiento de la edición en España en esta centuria ${ }^{13}$. A estas dificultades se une el hecho de que han desaparecido gran parte de los protocolos notariales de la ciudad salmantina durante la primera mitad del siglo XVI, circunstancia que también se aprecia en otras provincias españolas — caso de Zamora-. El vaciado completo de este fondo nos ha permitido localizar treinta y siete contratos firmados con impresores

9 La iniciativa de los alemanes en los inicios de la imprenta en España constituyó un fenómeno habitual en varias ciudades; sin embargo, la presencia posterior de extranjeros, como ya hemos apuntado, fue nula, mínima o muy limitada, como se aprecia en Lérida, Baeza, Logroño, Córdoba, Granada o Sevilla — en la segunda mitad del siglo XVI- En Valencia trabajaron al menos media docena de impresores franceses y flamencos. Véase, L. GONZÁLEZ y M. JIMÉNEZ CATALÁN, La imprenta en Lérida. Ensayo bibliográfico (14791917), Lleida, 1997, p. XVIII; Frederick J. NORTON, La imprenta en España. 1501-1520, Madrid, 1997; VV. AA. La imprenta en Granada, Granada, 1997; C. ÁLVAREZ MÁRQUEZ, La impresión y el comercio de libros en Sevilla. S. XVI, Sevilla, 2007; Ma. MARSÁ, La imprenta en la Rioja (siglos XVI-XVII), Madrid, 2002; M. BOSCH CANTALLOPS, Contribución al estudio de la imprenta en Valencia en el siglo XVI, I, Madrid, 1989; J. Ma VALDENEBRO CISNEROS, La imprenta en Córdoba. Ensayo bibliográfico, Madrid, 1900 [edición facsímil. Córdoba, 2002].

10 V. BÉCARES BOTAS, La compañia de libreros de Salamanca (1530-1534), Salamanca, 2003, p. 10; M. de la MANO GONZÁLEZ, Mercaderes e impresores de libros en la Salamanca del siglo XVI, Salamanca, 1998.

11 Para el conocimiento de algunos datos biográficos sobre impresores y libreros extranjeros que citaremos, véase J. DELGADO CASADO, Diccionario de impresores españoles (siglos XV-XVII), 2 tomos, Madrid, 1996.

12 M. de la MANO GONZÁLEZ, Op. cit.; D. E. RHODES, "Italy and Spain in the Fifteenth and Sixteenth Centuries: Connections in the Book Trade”, en P. M. CÁTEDRA y Ma . L. LÓPEZ-VIDRIERO, Op. cit., Tomo I, pp. 319-326.

13 Así lo ponen de relieve algunas publicaciones efectuadas sobre estas fuentes documentales. Véase C. PÉREZ PASTOR, "Escrituras de concierto para imprimir libros", Revista de Archivos, Bibliotecas y Museos, tercera época, I, 1897, pp. 363-371; F. J. LORENZO PINAR, "Los contratos de impresión de libros en Salamanca (1601-1625)", en Homenaje a Antonio Matilla Tascón, Zamora, 2002, pp. 417-442 y "Contratos de impresión de libros en Salamanca en el siglo XVII (1626-1650)", Pliegos de Bibliofilia, 21, (primer trimestre 2003), pp. 47-60; Ch. PELIGRY, "Du manuscrit a l'imprimé: le contract d'édition dasn l'Espagne du Siecle d'Or", en VV.AA. De l'alphabétisation aux circuits du livre en Espagne, XVIe-XVIIe siècles, París, 1987, pp. 333-343; A. GÓNZÁLEZ DE AMEZÚA, "Cómo se hacía un libro en nuestro siglo de Oro", Bibliografía Hispánica, V, Madrid, 1946, pp. 761-799; R. ESPINOSA MAESO, “Contratos de impresión de libros”, Boletín de la Real Academia Española, XIII, 1926, pp. 291-301; A. MATILLA TASCÓN, “Algunas escrituras relativas a autores y libros en la documentación notarial de Madrid", Anales del Instituto de Estudios Madrileños, XXXVI, 1996, pp. 297-300. 
extranjeros - suponen dos de cada tres de los documentos de este tipo conservados ya que el resto se concertó con tipógrafos castellanos-, correspondientes fundamentalmente a la segunda mitad del siglo XVI, sobre los que basaremos nuestro estudio; no obstante, también aludiremos a otras tipologías documentales - caso de los pleitos, las obligaciones o los poderes - las cuales constituyen fuentes históricas complementarias para obtener noticias indirectas de acuerdos entre impresores, editores y autores. A la hora de abordar estudios de este tipo también hemos de tener en cuenta que algunos conciertos se llevaron a cabo fuera de la Salamanca — se firmaron en Madrid o en Medina del Campo, entre otros lugares_-, hecho que contribuye a proporcionar una visión incompleta y provisional sobre el tema al no haber recurrido a ellos.

$\mathrm{Si}$ atendemos al elenco de obras proporcionado por Lorenzo Ruiz Fidalgo, los contratos conservados firmados por los impresores extranjeros asentados en la urbe apenas representaron un tres por ciento con respecto al número de ediciones citadas en su estudio tipobibliográfico. Aunque este volumen documental pueda parecer corto es mucho mayor que el manejado para otros estudios de carácter similar o frente a los que han superado los avatares del tiempo en otros centros impresores. Hay que valorarlos en su justa medida considerando, como ya lo hiciera Armando Petrucci, que son pocos los libros de cuya tirada poseemos una información precisa que nos permita conocer el número de ejemplares impresos para un determinado periodo o tipo de libros, lo que convierte a la información contenida en estos documentos, como ya hemos señalado, en indispensable para el conocimiento del mundo editorial de la época ${ }^{14}$.

Las cifras sobre contratos que han llegado hasta nosotros conducen a una primera apreciación: probablemente la contratación para editar un libro no requirió en la mayoría de las ocasiones de un fedatario público. Este hecho no resulta nada extraño si consideramos que sucedió algo similar con otros múltiples actos convenidos en este siglo XVI, caso de los conciertos para el servicio doméstico o agrícola, o el finiquito de cuentas tras la finalización de una curaduría o de una tutoría, donde el simple acuerdo verbal resultaba suficiente. Cabría preguntarse entonces si la realización de contratos de impresión ante escribano estuvo ligada a determinados tipos de obras, a situaciones especiales de las que se deseaba dejar constancia o a la desconfianza de una o de ambas partes contratantes frente a la entidad de la empresa editorial. Se trata de interrogantes de difícil respuesta por la variedad de situaciones y tipologías contractuales. Por otro lado, la firma de un concierto ante el escribano tampoco supuso en todos los casos que la obra llegase a ver la luz ${ }^{15}$.

14 A. PETRUCCI, Libros, editores y público en la Europa Moderna, Valencia, 1990, p. 30.

15 Así lo afirma Vicente Bécares para la Historia Natural de Plinio en romance del licenciado Luis de Villavicencio, colegial del Colegio Mayor de Cuenca. En el momento del concierto con Juan Boyer y Ambrosio Duport, vecinos de Medina del Campo, faltaba parte del libro por traducir, hacer las tablas y tenía que ser corregido por el maestro Francisco Sánchez, catedrático de Retórica. No lo hemos incluido en el anexo tanto por esta circunstancia, como por estar editado por extranjeros no asentados en Salamanca, aunque efectuasen en esta ciudad parte de sus negocios. Carlos Santos Fernández en su estudio sobre el libro en Galicia en el siglo XVII, afirma, en esta misma línea, que los textos a los que aluden los documentos contractuales puede que en algunos casos no llegaran a ver la luz y sólo se haya conservado el testimonio documental. Archivo Histórico Provincial de Salamanca (en adelante A. H. P. Sa). Protocolos Notariales (en adelante P. N.). Legajo (en adelante Leg.) 3222. 20-III-1597. Fols. 541-544. Véase, V. BÉCARES BOTAS, Librerías salmantinas del siglo XVI, Segovia, 2007, p. 18; C. SANTOS FERNÁNDEZ, "Documentos para la historia del libro en Galicia: ge- 
A través de la documentación salmantina trataremos de conocer las condiciones que se pactaron relacionadas con la financiación de las obras a imprimir, los derechos de autor, el número de ejemplares, el tipo de letra o de papel, los modelos de referencia, el tiempo para realizar la edición, el número de prensas utilizado, las condiciones para la corrección de pruebas y las penalizaciones ante las posibles infracciones contractuales. Analizaremos si estos compromisos siguieron pautas estereotipadas o por el contrario remarcaron aspectos concretos de interés para autores y editores. Al margen de estos objetivos, igualmente nos interesa conocer quiénes fueron los extranjeros involucrados en la edición y si necesitaron de la formación de compañías para sus empresas, así como los problemas suscitados en el desarrollo de la actividad tipográfica.

Aunque para este estudio, como ya hemos señalado, partimos de la base de unos contratos concretos - relacionados en el anexo-, haremos alusión a otros acuerdos e informaciones parciales o indirectas que no siempre pueden ser interpretadas de manera exacta. Es el caso de los datos proporcionados sobre el volumen de determinadas ediciones. Así por ejemplo, en uno de los documentos conservados se indica que María de Neila - probablemente en compañía de Octaviano Parente-, imprimió diferentes obras que envió a Benito Boyer, lionés, a Medina del Campo, entre ellas 500 Virgilios, 500 Terencios y 500 Fábulas de Esopo ${ }^{16}$. Nos queda la duda de si estas cifras supusieron el total de la edición de cada una de las obras o eran tan sólo una parte de la misma. Son interrogantes a los que no da respuesta la documentación.

\section{Las condiciones contractuales}

Desde el punto de vista diplomático la estructura de estos documentos, que aparecen como cartas, cartas de obligación, de concierto, de iguala o de conveniencia, no difiere en gran medida de la que han señalado los estudios sobre protocolos notariales para estas tipologías documentales ${ }^{17}$. Podían ir acompañados de poderes, licencias o memorias con las condiciones contractuales. Suelen iniciarse habitualmente por una notificatio del estilo "conosçida cosa sea", "sepan quantos esta pública escritura..." o "sepan quantos esta carta vieren", y en menor media por la data tópica y crónica. Su dispositio, la parte del documento más sustancial para aproximarnos a la edición del libro, difiere en cuanto a la información de unos a otros. Puede ir redactada en cláusulas precedidas por un "iten" o sin una estructuración precisa. La sanctio o corroboratio, que asegura el cumplimiento de esta parte dispositiva y garantiza que se han guardado las formalidades jurídicas para validar el documento, incluye frecuentemente cláusulas sancionativas obligatorias — para

neradores, intermediarios y consumidores compostelanos (1600-1622)", Cuadernos de estudios gallegos, 121, (2008), p. 265.

16 En algunos documentos de 1578 aparece asociada con Octaviano. A. H. P. Sa. P. N. Leg. 4621. 10-III-1579. Fols. 758-777; Leg. 4620. 3-VIII-1578. Fols. 1559-1561.

17 N. ÁVILA SEOANE, Estructura documental. Guía para alumnos de Diplomática, Gijón, 2014; J. BONO Y HUERTA, "Formularios notariales españoles de los siglos XVI, XVII y XVIII", Anales de la Academia Matritense del Notariado, 22 (1980), pp. 287-318 y Los archivos notariales, Sevilla, 1985; M D. ROJAS VACA, "El documento notarial de Castilla en época moderna", Boletín de la Sociedad Española de Ciencias y Técnicas Historiográficas, 3 (2005), pp. 65-126. 
cumplir lo estipulado - , renunciativas - a leyes generales, fueros, derechos, etc.y penales para el caso de incumplirse lo concertado.

Atendiendo a la parte dispositiva del documento, la entrega de originales de los autores a los impresores o editores constituye uno de los aspectos de los que apenas han quedado huellas en los contratos de edición. En el acuerdo para imprimir la Glosa al Ordenamiento Real del doctor Diego Pérez, catedrático de Clementinas de la Universidad de Salamanca, rubricado en marzo de 1557, se exigía que el texto fuese proprocionado dos semanas después de la firma del contrato, "en latín, corregido e honesto en perfizión", pena de una elevada multa de 50 ducados si el autor no cumplía con el plazo de entrega, destinada a los impresores - los florentinos Juan María de Terranova y Jacobo de Liarcari- y a los oficiales de imprenta ${ }^{18}$.

Para poder realizar la edición de estos originales y evitar problemas legales resultaba imprescindible contar con la licencia del Consejo Real de Castilla, formalidad que se dejó en ocasiones en manos de los editores. En algún contrato, ante la carencia de la misma se estableció un plazo de tres meses para conseguirla con el objeto de no retrasar la publicación. También, aunque sin fijar una fecha concreta, se podía exigir al autor que procurase obtener "dicha merced... con todo cuidado y diligencia" ${ }^{\prime 9}$. Cuando este no financiaba personalmente su obra, solía comprometerse a otorgar un poder a los libreros o editores concediéndoles la exclusividad para la impresión de la misma durante los diez años de duración de la licencia con la finalidad de compensar la inversión ${ }^{20}$.

Los contratos resultan más explícitos a la hora de acercarnos a las formas de financiación de las obras. La predominante fue aquella en la que el autor o una institución, habitualmente religiosa, autofinanciaron la obra, sin que esta tendencia sea necesariamente extensible a todo el volumen de obras editadas en esta centuria. La institución, el autor, glosador o persona encargada de la edición se comprometía a abonar una cantidad al impresor por pliego. En la tercera impresión de las Siete Partidas glosadas por el licenciado Gregorio López, gestionada a través del doctor Tomás de Tobar, Fiscal Real en la Chancillería vallisoletana, se fijaron 3 maravedíes por pliego, quedando el papel a costa del impresor Domingo de Portonaris Ursinos $^{21}$. El gasto ascendería a un total de 3.000 ducados abonados a plazos. Al autor, no obstante, se le concedió la posibilidad de pagar la mitad de la edición en ejemplares de la obra con la condición de que en un periodo de tres meses no se pudiesen vender más volúmenes que los de los impresores para evitar la competencia $^{22}$.

18 A. H. P. Sa. P. N. Leg. 2934. 17-III-1557. Fol. 362.

19 A. H. P. Sa. P. N. 2934. 17-III-1557. Fol. 362.

20 Empleamos el concepto de autor de una manera amplia, en relación no solamente con quien escribía o hacía circular una obra, sino también con quien la compilaba, glosaba o comentaba. Sobre el concepto de autoría, véase R. CHARTIER, El orden de los libros. Lectores, autores y bibliotecas entre los siglos XIV-XVIII, Barcelona, 1994, p. 53.

21 La documentación alude igualmente a varios poderes del impresor Andrea de Portonaris — de familia oriunda de Trino en el Monferrato- para que pudiese cobrar dinero a cuenta de la impresión de Las Siete Partidas, glosadas por el licenciado Gregorio López, del Consejo de Indias, que corresponden a la edición efectuada con anterioridad. A. H. P. Sa. Leg. 4074. 9-II-1554. Fol. 369-370; Leg. 3186. 1574. Fols. 523-530; Leg. 3188. 16-II-1576. Fols. 238-239.

22 Parte del dinero se cobró de las rentas que el doctor tenía en las minas de Alcudia y en la seda de Granada. A. H. P. Sa. P.N . Leg. 3186. 1574. Fols. 523-530; Leg. 4074. 9-II-1554. Fols. 369-370. 
Si se efectuaba una tirada de múltiples obras se podía llegar a un precio común por pliego para todas. Don Gaspar de Zúñiga y Avellaneda, obispo de Segovia, mandó imprimir a Andrea Portonaris diferentes libros litúrgicos para su obispado concertándose a 3,5 maravedíes por pliego "una obra con otra", es decir, compensando las que tuviesen un mayor tamaño de papel con las de menor ${ }^{23}$. Para los misales entregaría 300 ducados al contado y otros 100 ducados al mes. Para el resto de las obras no se adelantaría dinero. Parte de ellas, además, no estaba financiaba personalmente por el prelado. Se indicaba en el documento que los mayordomos de las iglesias de Segovia estarían obligados a pagar el precio que montase la impresión de los breviarios dos meses después de finalizada y actuarían además como fiadores de la misma.

Aunque no aparece de manera explícita, como han señalado algunos trabajos, la dedicación de una obra a un personaje de relieve buscaba por parte del autor la obtención de algún apoyo económico que cubriese al menos parte de sus gastos ${ }^{24}$. No se trató de un recurso muy empleado entre quienes publicaron en Salamanca ya que apenas representa a uno de cada diez contratos y en algunos casos estamos ante individuos con una posición social de cierto relieve, por lo cual no parece que la posible compensación crematística constituyese el principal objetivo de tal reconocimiento. En estos casos, entre las condiciones estipuladas se exigía, además de la presencia de la dedicatoria en el libro, la de las armas del benefactor o mecenas. Francisco de Avilés concertó con Vicente de Portonaris, hijo de un librero lionés, que figurasen las del duque de Alburquerque en la obra que había compuesto su padre - Avilés, sobre el capitulo de Corregidores - ${ }^{25}$. El doctor Pedro Núñez de Avendaño incorporó entre los requisitos de impresión de su obra una dedicatoria al arzobispo de Cuenca y en el Diccionario Castellano otra a su señor don Íñigo de Mendoza, duque del Infantazgo ${ }^{26}$.

La plasmación de las armas de determinado personaje pudo responder también a razones de prestigio y honor. Fue el caso de don Gaspar de Zúñiga y Avellaneda, miembro del Consejo Real y obispo de Segovia, quien obligó a que estuviesen presentes las suyas en las obras litúrgicas de su obispado, conforme a una muestra que le había entregado a Andrea de Portonaris y, además, sin que tal aditamento supusiese coste alguno para el prelado. En el caso de no hallarse plancha para imprimirlas en Salamanca, el coste de traerlas se pagaría por mitad entre el impresor y el autor quedando el molde para el primero ${ }^{27}$. La documentación hace referencia a algunas imprentas salmantinas que contaron con planchas para las ilustraciones,

23 En la operación actuaron como sus fiadores el escribano Sebastián de Ledesma y el mercader Antonio de Ledesma. Los precios debieron variar en función de la calidad del papel y de la tinta. Diego Núñez de Alba pagó a razón de 3 blancas por pliego de su obra Diálogos de la Jornada de Alemania. En la edición de los misales encargados por el monasterio de Nuestra Señora de Loreto de Salamanca, de la orden de San Bernardo, se abonaron a razón de 4,5 maravedíes por pliego para los de menor calidad y 6,5 maravedíes para los de marca mayor. A. H. P. Sa. P. N. Leg. 3874. 18-VII-1556. Fols. 323-333; Leg. 4073. 24-IX-1552. Fol. 957; Leg. 4870. 13-XI-1589. Fol. 1300 r.

24 Klaus Wagner las considera como una "treta del autor" de cara a lograr dinero o alguna joya. Véase, Klaus WAGNER, "De la imprenta de Gutenberg a las tipografías hispanas en América", en M. PEÑA DÍAZ y J. SOLANA PUJALTE (coords.), La cultura del libro en la Edad Moderna. Andalucía y América, Córdoba, 2001, p. 14.

25 A. H. P. Sa. P. N. Leg. 3189. 13-VII-1576. Fols. 317-318.

26 A. H. P. Sa. P. N. Leg. 3651. 23-V-1553. Fols. 183-184.

27 A. H. P. Sa. P. N. Leg. 4857. 22-VII-1573. Fols. 263-267. 
entre ellas la de Juan María de Terranova quien poseía 12 figuras de cobre para horas "e otras figuras e hystorias para diversas cosas, de madera" 28 . En la escritura de reparto de los bienes de Isabel de Basilea, tras el fallecimiento de su esposo Juan de Junta, de origen familiar italiano, mercader de libros, también se mencionan "figuras buenas y medianas, así de las horas como las del misal nuevo" de las que pasaron a disponer Felipe de Junta — hijo de Isabel de Basilea y Juan de Junta, nacido en Burgos ${ }^{29}$ - y Matías Gast, antuerpiense, junto a su mujer Lucrecia de Junta $^{30}$.

El dinero necesario para la impresión solía proporcionarse al impresor, como hemos aludido anteriormente, de manera fraccionada ${ }^{31}$. Tras un pago inicial, generalmente destinado a la compra de papel, el resto podía estar asociado a diferentes fases de la edición e incluso de la venta ${ }^{32}$. En la impresión de los Diálogos de la Jornada de Alemania de Diego Núñez, el autor adelantó 24 ducados y se comprometió a abonar la mitad del precio a los dos meses de iniciada la impresión, "tomando en cuenta los libros que se hubiesen vendido"33. En alguno de los contratos se especifica que hasta no efectuarse el último de estos pagos fragmentados el autor no podría sacar los libros del taller del impresor ${ }^{34}$. Esto no sucedía con obras de fácil salida al mercado, como las de fray Domingo de Soto, compradas inmediatamente tras finalizarse el trabajo, aunque no fuese barato el precio de los ejemplares. Así se aprecia con la adquisición de 700 cuerpos de libros de la obra De Iustitia et Iure por los que Andrea de Portonaris abonó 13.300 reales, a razón de 19 reales por libro $^{35}$.

Otra forma de financiación fue la que hizo recaer el pago de la edición en los impresores y libreros salmantinos, profesiones que en ocasiones estuvieron ambas ligadas en una misma persona. El interés de estos profesionales del libro se centró en algunas obras de fácil venta como eran las de fray Luis de Granada -Libro de la Oración y Guía de Pecadores, Catecismo y obras en romance ${ }^{36}$-;

28 Los misales encargados por el convento salmantino de Nuestra Señora de Loreto para la orden de San Bernardo irían estampados con estampas finas abriéndolas "conforme a la traça" dada a los impresores - Juan Fernández y Juan Pulman-. Si el padre abad deseaba quedarse con las planchas originales se las pagaría a los impresores. A. H. P. Sa. P. N. Leg. 2942. 19-III-1557. Fol. 243r; Leg. 4870. 13-XI-1589. Fol. 1300 v.

29 M. FERNÁNDEZ VALLADARES, La imprenta en Burgos (1501-1600), Madrid, 2005, p. 173.

30 Esta mención a materiales para ilustrar horas está en consonancia con la demanda de este tipo de obras las cuales constituyeron los libros más comunes de las prácticas religiosas individuales tanto en España como en Francia. A. H. P. Sa. P. N. Leg. 3875. VII-1561. Fols. 321-329. Véase R. CHARTIER, (dir.), Les usages de l'imprimé (XVe-XIXe siècle), Paris, 1987, p. 189.

31 A. H. P. Sa. P. N. Leg. 3206. 2-I-1588. Obligación del licenciado Diego de Tapia Aldana. Fols. 17-18.

32 Era costumbre en la ciudad que del gasto del papel un dos por ciento quedara como refracción para el impresor, probablemente para compensar el defectuoso o el utilizado en pruebas y erratas. A. H. P. Sa. P. N. Leg. 3667. 1590. Fols. 321-324.

33 A. H. P. Sa. P. N. Leg. 4073. 24-IX-1552. Fol. 957.

34 A. H. P. Sa. P. N. Leg. 4857. 22-VII-1573. Fols. 263-267.

35 Se trataba de una obra de fácil comercializaión si tenemos en cuenta que incluso años después, en 1582, ocho libreros lioneses se unieron para imprimirla y competir con las ediciones españolas, aunque parece que no tuvieron éxito en su objetivo. A. H. P. Sa. P. N. Leg. 4074. 6-IV-1554. Fol. 867. Véase, G. MORISSE, "El comercio de libros de Lyon en Castilla en el siglo XVI. El caso de Medina del Campo", en VV.AA., Libros y ferias..., Op. cit., p. 51.

36 Manuel Peña Díaz lo considera como uno de los autores más reeditados a lo largo del siglo XVI y presente en varias bibliotecas de la época. Carlos Alberto González afirma que los registros de navíos y los inventarios post-mortem ratifican a este divulgador de la meditación como uno de los más difundidos en las colonias españolas durante los siglos XVI y XVII. M. PEÑA DÍAZ, El laberinto de los libros. Historia cultural de la 
las de carácter jurídico — El ordenamiento Real; Capítulo de Corregidores-; las religiosas - Biblia de Vatablo y Breve instrucción de confesores - o lingüísticas -Diccionario castellano-.

Entre las condiciones financieras también se aceptó el abono de parte de los gastos con una cierta cantidad de libros impresos. Vicente Millis o Milles, italiano, acordó con María de Neila, la viuda de Juan María de Terranova, que imprimiese 1.000 ejemplares de la obra de Palacios Rubios. Vendió 300 libros y dejó que María pudiese hacer lo mismo con otros 300 en un plazo de seis meses. Los 400 volúmenes restantes se los abonaría en cuatro meses y de no hacerlo pasarían a manos de María para sufragar los costes de la impresión ${ }^{37}$. En líneas generales la obra se pagaba a medida que avanzaba el trabajo tipográfico, como puede apreciarse, entre otros contratos, en el que Benito Boyer, lionés, mercader de Medina del Campo, estableció con los herederos de Juan María de Terranova sobre el segundo tomo del libro Cuarto de las Sentencias de Domingo de Soto ${ }^{38}$. Se le liquidarían 7 reales por resma impresa y 7 ducados por cada prensa que estuviese trabajando - habría dos en funcionamiento- ${ }^{39}$. Proporcionaría además el papel con un 2 por ciento de refracción, porcentaje acostumbrado, como hemos señalado, en aquella época ${ }^{40}$.

La casuística no se redujo a la de los contratos apuntados. Hubo situaciones en las que, a pesar de que la edición corriese a cargo del impresor o del librero, se exigió al autor o glosador una cantidad en préstamo para facilitar la publicación. La devolución de este dinero se podía garantizar mediante una fianza monetaria o en objetos de oro o de plata. En el caso de que el autor o glosador perteneciese al gremio de la Universidad salmantina, tales piezas se depositarían en el arca de la institución académica. Los doctores solían conseguir este peculio mediante un préstamo que podía obtenerse conforme a los estatutos universitarios. Los beneficiarios se comprometían a reintegrar el dinero a la Universidad sin intereses en el plazo de un año ${ }^{41}$.

En la edición de la obra de fray Antonio Rubio, este clérigo anticipó 2.100 reales a Juan de Cánova, tipógrafo borgoñón, comprometiéndose este impresor a reembolsarlos a don Juan de San Millán, obispo de León, quien parece que, a su vez, se los había prestado al fraile. Lo haría una vez hubiese vendido ejemplares por valor de 200 ducados - 2.200 reales - y con la obligación de "que cada vez que le pidiere al dicho Juan de Cánova que le declare con juramento si ha vendido ducientos ducados de los dichos libros sea obligado a lo declarar, e declarado que los ha vendido sea obligado a volver e pagar los dichos dos mil e çien reales" ${ }^{42}$. En

Barcelona del Quinientos. Madrid, 1997, p. 20; C. A. GONZÁLEZ SÁNCHEZ, "Un océano de libros: la carrera de Indias en el siglo XVI", en M. PEÑA DÍAZ y J. SOLANA PUJALTE (coords.), La cultura ..., Op. cit., p. 249.

37 A. H. P. Sa. P. N. Leg. 4625. 21-I-1580. Fols. 1631-1633.

38 Parte de los datos biográficos de este librero pueden consultarse en V. BÉCARES BOTAS y A. LUIS IGLESIAS, La librería de Benito Boyer. Medina del Campo. 1592, Valladolid, 1992.

39 En los contratos se habla de papel del número dos y del número uno. El libro estaba finalizado en marzo de 1579. A. H. P. Sa. P. N. Leg. 4619. 9-VII-1578. Fols. 212-215; Leg. 4620. 3-VIII-1578. Fols. 1559-1561 y 2VIII-1578. Fols. 1562-1563; Leg. 4621. 10-III-1579. Fol. 757 y 10-III-1579. Fols. 758-777.

40 Este porcentaje es expresado de diferentes modos: una mano por cada tres resmas, o dos resmas perdidas por cada cien. A. H. P. Sa. P. N. Leg. 4640. 19-I-1587. Fols. 2238-2247.

41 El doctor Diego Pérez, catedrático de Clementinas, se comprometió a adelantar 200 ducados a Juan María de Terranova y a Jacobo Liarcari para la impresión de su obra con un préstamo de la institución académica. A. H. P. Sa. P. N. Leg. 2934. 17-III-1557. Fol. 362.

42 A. H. P. Sa. P. N. Leg. 4853. 1-IX-1567. Fols. 348-350. 
la impresión de los repertorios de la Glosa de la segunda parte del Ordenamiento Real del doctor Diego Pérez, la mitad del coste iría a cargo del autor y la otra del impresor Vicencio Portonaris - hijo del lionés Domingo de Portonaris- ${ }^{43}$.

También hallamos circunstancias en las que, aunque la edición recayó en el autor, se abrió la posibilidad de participar al impresor en la financiación. En la publicación de las Reglas de Derecho del doctor Pedro de Dueñas, miembro de la Universidad salmantina, a cargo de Andrea de Portonaris, el impresor podía quedarse, si quería, con la mitad de los volúmenes descontándoselos del precio final, e incluso con la totalidad de la impresión si el autor no deseaba subvencionarla con su dinero. En caso de cofinanciación, autor e impresor actuarían "en compañía", repartiéndose por iguales partes las ganancias ${ }^{44}$.

La documentación contractual también pone el énfasis en los beneficios o "derechos" a percibir por las partes contratantes. Los autores cuando no financiaban la impresión podían tener como compensación dinero en efectivo —osciló entre los 800 y 3.000 reales, siendo estos últimos los que percibió Francisco Avilés-; una serie de ejemplares —entre 12 y $250^{45}$-, bien del libro objeto de impresión o de otros de la tienda del librero, sin que excediesen el valor de las obras pactadas; o bien ambas cosas: libros y dinero ${ }^{46}$. Si el privilegio permitía una segunda impresión, el número de volúmenes entregados al autor o glosador en ediciones posteriores podía variar, como sucedió con el Ordenamiento Real del doctor Diego Pérez. Recibió 55 ejemplares por una impresión del año 1557 y 104 en la del año de $1573^{47}$.

Si el autor o glosador deseaba libros de la obra impresa se le daban de los primeros que saliesen de los talleres ${ }^{48}$. También podía acceder a conseguir volúmenes extra, además de los ligados a sus derechos, al precio de la tasa y durante un determinado tiempo que no excediese el año y medio ${ }^{49}$. En caso de ser miembro de la comunidad universitaria se le entregaban 10 ejemplares para regalarlos a los doctores de la Universidad. Cinco de ellos a cargo de los editores y otros cinco del autor o glosador. Lo mismo sucedía con las instituciones conventuales que además de ejemplares solían recibir una cierta cantidad monetaria ${ }^{50}$. Al margen de los libros destinados al autor, los impresores tenían que proporcionar obras gratuitas a los oidores del Consejo Real. En ocasiones, como en la impresión de la obra del doctor

43 A. H. P. Sa. P. N. Leg. 3184. 8-XII-1573. Fols. 1015-1020.

44 Se estableció que autor adelantase 50 ducados a la hora del contrato, diese otros 50 al iniciar la impresión y otros 3 para ayuda del corrector. Cada pliego del libro - de unos 40 pliegos aproximadamente-, se abonaría a tres blancas. A. H. P. Sa. P. N. Leg. 4073. 29-XII-1553. Fols. 955-956; Leg. 4074. 10-II-1554. Fol. 893.

45 La cifra más elevada en libros la encontramos en el contrato de Francisco Arias por su Aprovechamiento espiritual, quien recibió 250 ejemplares de cada uno de los dos tomos. Esta obra, aunque se contrató en Salamanca por Juan Boyer, vecino de Medina del Campo, aparece impresa en Valladolid y por tanto no la incluimos en el anexo. A. H. P. Sa. P. N. Leg. 4871. 4-V-1592. Fols. 306-307. Véase, Ma MARSÁ VILÁ, Materiales para una historia de la imprenta en Valladolid. (Siglos XVI y XVII), León, 2007, p. 160.

46 En la edición de uno de los tratados del licenciado y abogado placentino Juan Gutiérrez se indicaba que le entregaría al autor el original y 12 ejemplares "para dar a sus amigos". Generalmente los conventos que tenían los derechos de autor de las obras de fray Luis de Granada recibían dinero y obras del fraile. Además de este religioso, el único que percibió una cuantía monetaria y a la vez ejemplares fue Francisco de Avilés. A. H. P. Sa. P. N. Leg. 4857. 22-VII-1553. Fols. 263-267.

47 A. H. P. Sa. P. N. Leg. 3184. 8-XII-1573. Fols. 1015-1020.

48 A. H. P. Sa. P. N. Leg. 2934. 17-III-1557. Fol. 362.

49 A. H. P. Sa. P. N. Leg. 3184. 8-XII-1573. Fols. 1015-1020.

50 A. H. P. Sa. P. N. Leg. 2942. Fols. 510-515. 
Diego Pérez, el volumen destinado al presidente de la citada institución o a algún prelado se realizaba en papel especial "de marquilla, bueno" ${ }^{51}$. A diferencia de otras ciudades, como Toledo, no hallamos cláusulas contractuales que limiten el número de ejemplares que el autor podía regalar o que le impidiesen venderlos hasta que el impresor hubiese liquidado los suyos ${ }^{52}$.

Los pagos monetarios por derechos de autoría podían ir destinados directamente al autor o a alguno de sus familiares, como sucedió con la obra del doctor Francisco de Avilés - Capitulos de Corregidores - por la cual Vicencio de Portonaris abonó 3.000 reales al hijo del autor, del mismo nombre, alcalde de Alburquerque y Corregidor de La Codosera. A cambio de tal cantidad obtuvo licencia para editarlo durante seis años ${ }^{53}$. Condiciones similares se repitieron tras finalizar dicho período cuando se concertaron para una nueva edición ${ }^{54}$. Los Portonaris se comprometieron a dar 1.100 reales al doctor Diego Pérez por editar su obra, además de 100 “cuerpos" de dicha impresión o el precio de los mismos según la tasa.

En las ediciones relacionadas con clérigos regulares, los beneficios podían recaer en sus órdenes. El dinero abonado por el impresor a la congregación religiosa fue catalogado en alguna ocasión como una "limosna" — de este modo se califica el recibido por el convento salmantino de San Francisco por la impresión de las Homilías de fray Alonso de Castro- ${ }^{55}$. El convento de San Pablo de Burgos obtuvo pingües beneficios económicos por la obra de Domingo de Soto, además de 10 ejemplares de cada una de las ediciones encargadas al mercader florentino Leonardo Nicolocio ${ }^{56}$. A cambio de estas contraprestaciones los autores se comprometían a no imprimir la obra con otro tipógrafo hasta que no se hubiese agotado la edición. En caso contrario deberían adquirir todos los ejemplares que faltasen de vender por parte del impresor al precio que él los facilitaba a los libreros ${ }^{57}$.

Al margen de las cláusulas de tipo económico, los contratos fijan su atención en los aspectos tipográficos - tipos de letras, tinta, corrección del texto, etc.-, en el número de ejemplares a imprimir, el ritmo de trabajo de las prensas o las indemnizaciones frente a posibles fraudes, dilaciones y variaciones en el resultado final de la obra. Las cláusulas contractuales suelen conminar al impresor a que efectúe su trabajo "fielmente", conforme al ejemplar o muestras entregadas por el autor ${ }^{58}$; o

51 Sucedió con dos volúmenes del Ordenamiento Real del doctor Diego Pérez, catedrático de Cánones de la universidad salmantina, entregados a Diego de Covarrubias, obispo de Segovia y presidente del citado Consejo, y a don Pedro de Luna, obispo de Tarazona. El resto serían de papel ordinario del número dos. Otras veces la impresión completa fue de marquilla, como el Comentario sobre los doce profetas menores del doctor Francisco de Ribera, o el Oficio Defuntorum de don Gonzalo de Solórzano. A. H. P. Sa. P. N. Leg. 3184. 8-XII-1573. Fols. 1015-1020; Leg. 4640. 23-XII-1587. Fols. 2268-2271 y 19-I-1587. Fols. 2238-2242; Leg. 2947. 27-X-1571. Fols. 686-687.

52 H. RODRÍGUEZ DE GRACIA, “Contratos de impresión suscritos por Juan de Mariana, Alonso de Villegas y Francisco de Pisa", Hispania Sacra, 111, (2003), p. 65.

53 A. H. P. Sa. P. N. Leg. 3180. 23-XI-1570. Fols. 536-537; Leg. 3181. 28-XII-1570. Fols. 43-44.

54 Además de una cantidad monetaria idéntica, el hijo del autor recibiría 12 cuerpos de libro - 11 en papel y uno encuadernado - y una nueva recopilación con su repertorio. El dinero se abonaría en tres plazos - junio de los años 1578,1580 y 1582 - , probablemente a medida que se fuese dando salida a los libros. A. H. P. Sa. P. N. Leg. 3189. 13-VII-1576. Fols. 317-318.

55 A. H. P. Sa. P. N. Leg. 4853. 31-XII-1567. Fols. 338-339.

56 A. H. P. Sa. P. N. Leg. 2942. 10-V-1567. Fols. 510-515.

57 A. H. P. Sa. P. N. Leg. 4853. 9-VI-1567. Fols. 346-347.

58 En el acuerdo entre Andrea de Portonaris, impresor real, con don Gaspar de Zúñiga y Avellaneda, obispo de Segovia, para imprimir diferentes libros litúrgicos, cada una de las partes se quedó con una muestra. Manuel 
bien imitar las pautas seguidas en impresiones previas "sin que se haga mudanza en glosa o en letra alguna" - como se aprecia en las condiciones sobre la glosa a las Siete Partidas del licenciado Gregorio López; o en la Glosa sobre la segunda parte del Ordenamiento Real del doctor salmantino Diego Pérez, en la que Vicente Portonaris estaba obligado a imitar el modelo de esta misma obra impresa en los talleres de Juan María de Terranova y que, a su vez, copiaba la citada glosa de Gregorio López "con sus señales, e divisiones e diferençias de letras que fueren necesarias" -59 .

Entre los aspectos formales, los relativos al papel sobre el que se imprimía la obra fueron los que recibieron una mayor consideración; en segundo plano quedaron los relacionados con el formato y las tintas; y, en menor medida, los que tuvieron que ver con las encuadernaciones. Se suelen indicar algunos rasgos que deberían caracterizar al papel: tipo de pliego — común—, dimensiones — cuarto-, la calidad - de marquilla, del número uno o dos-, la procedencia y, excepcionalmente, el peso ${ }^{60}$. En algún contrato se realizó con una gran precisión dejando algún ejemplar en manos del escribano para que no quedasen dudas al respecto ${ }^{61}$.

Los impresores extranjeros solían comprarlo, al igual que los nacionales, en Segovia $^{62}$; de los mercaderes de Medina del Campo ${ }^{63}$-algunos de los cuales lo importaban a su vez de Génova- ${ }^{64}$; o de Francia ${ }^{65}$. Los Portonaris hicieron adquisiciones de papel de doña Isabel de Torres y Arévalo, viuda de Gaspar Tomás Fabio,

José Pedraza indica que se confeccionaban muestras ex profeso de alguna o algunas páginas de la obra a imprimir, a veces anexas a los contratos, con el fin de evitar diferencias de interpretación sobre asuntos técnicos. A. H. P. Sa. P. N. Leg. 3874. 10-VII-1556. Fols. 234-239. M. J. PEDRAZA GRACIA, El libro español del Renacimiento. La "vida" del libro en las fuentes documentales contemporáneas. Madrid, 2008, p. 154.

59 Pina de Rosas del canónigo santiagués Lorenzo Osorio Barba se imprimiría con letra redonda, de la misma forma que el libro de fray Luis de León, "catedrático de la Universidad de Salamanca, Sobre los cantares". A. H. P. Sa. P. N. Leg. 3184. 8-XII-1573. Fols. 1015-1020; Leg. 2934. 17-III-1557. Fol. 362; Leg. 3209. 19-IX1589. Fols. 117-119.

60 El obispo de Segovia exigía en el contrato con Andrea de Portonaris que la resma de papel de los manuales, procesionarios y misales pesase 20 libras; la del breviario de cámara 12 libras; la del breviario pequeño 11 libras y la del diurnal 9 libras. Además indicaba que fuese "blanco y de buena pasta, sin motas, so pena que lo tornare a hacer". A. H. P. Sa. P. N. Leg. 3874. 10-VII-1556. Fols. 234-239; Leg. 4640. 23-XII-1587. Fols. 2268-2271.

61 Caso de la Glosa a las Siete Partidas del licenciado Gregorio López: “... será de la marca, tamaño, grosor, cuerpo, blancura y fineza de un pliego que se mostró al tiempo del concierto que es de la Segunda Partida del título 29, la primera hoja y 31 la segunda hoja, que el número de la primera es 110 y de la segunda $115 \mathrm{y}$ el pliego está firmado de ambas hojas y que dicho pliego quedará en manos del escribano". A. H. P. Sa. P. N. Leg. 3186. 1574. Fols. 523-530; Leg. 3187. 26-X-1574. Fols. 118-132; Leg. 3188. 24-II-1576. Fols. $294-300$.

62 A. H. P. Sa. P. N. Leg. 3181. 26-II-1570. Fols. 192-193; Leg. 3190. 5-V-1579. Fols. 704-705; Leg. 3187. 26X-1574. Fols. 118-132.

63 Entre los proveedores estuvo Francisco Forniel quien mantuvo un pleito con Andrea de Portonaris por el impago de una partida de papel que se había traído de El Puerto. Archivo de la Real Chancillería de Valladolid (en adelante A. R. Ch. Va.). Registro de Ejecutorias. Caja 100, 14. 7-IV-1563.

64 Especialmente del papel del número uno. Se trataba de un papel empleado fundamentalmente en obras litúrgicas. A. H. P. Sa. P. N. Leg. 3662. 11-VII-1579. Obligación de Pedro de Portonaris, impresor, en favor de Juan Delgado, mercader, vecino de Medina del Campo. Fol. 472; Leg. 4073. 3-X-1552. Fol. 685; Leg. 4617. 18-II1577. Fol. 583. Véase, C. PÉREZ PASTOR, La imprenta en Medina del Campo, Valladolid, 1992, p. 419 ; I. C. DÍEZ MÉNGEZ, "Ensayo de un estudio del papel en el taller salmantino de Juan de Cánova a través de algunos ejemplares existentes en la Biblioteca Histórica de la Universidad Complutense de Madrid", Pecia complutense: Boletín de la Biblioteca Histórica "Marqués de Valdecilla", 24, (2016), p. 2.

65 El impresor Andrea de Portonaris dio su poder a Andrés Duboys, vecino de Nantes, para que pudiese recibir libros y papel que le enviase Guillermo Roville, vecino de Lyon, los cuales se remitirían a España por barco. El libro del licenciado Diego de Tapia Aldana se imprimió con papel número uno de Francia. A. H. P. Sa. P. N. Leg. 4074. 1-V-1554. Fol. 415; Leg. 4640. 6-V-1587. Fols. 2348-2349. 
segoviana. Se fabricaba en los molinos legados por su marido en Palazuelos de Eresma. Solía ser de calidad inferior al de importación, a tenor de las afirmaciones que aparecen en los contratos. Para la impresión del Tractatus de juramento confirmatorio et aliis yn jure variis resoluçionibus, el doctor Antonio Guerrero, quien negoció la edición con la viuda de Juan de Cánova, indicaba que fuese "en papel muy blanco, bueno, de marca común de Francia y no de Segovia"66. En algún contrato se exigió que el papel fuese igual al de la muestra dejada ante escribano, para evitar fraudes en la calidad; o al empleado en determinada obra — caso del utilizado en la Glosa de las Siete Partidas del licenciado Gregorio López por Andrea de Portonaris $-{ }^{67}$. A finales de siglo aparece algún concierto en el que se cita otra zona de procedencia como la madrileña de El Paular ${ }^{68}$. Los intentos que hubo en la zona de Ledesma - Olmillos - de crear un molino papelero por parte de Juan Periel resultaron infructuosos ante las crecidas del río ${ }^{69}$.

Las compras de papel, que podían requerir una elevada inversión - entre las documentadas alguna llegó a los 43.140 reales-, se abonaban a plazos, en ocasiones efectuados cuando los tipógrafos recibían parte del dinero de la impresión de una determinada obra o al finalizar la misma. La adquisición solía hacerse con varios meses de antelación - hasta ocho - para evitar interrupciones en las prensas siendo transportado a Salamanca a consta del proveedor. A veces una pequeña parte de la deuda contraída por la adquisición del papel se podía abonar en ejemplares de la edición ${ }^{70}$. Resultó menos frecuente que lo proporcionasen a los impresores los autores o las instituciones a las que pertenecían, caso de lo sucedido con la obra del doctor Francisco de Ribera que fue suministrado por la Compañía de Jesús de la que era miembro. Otros tipos de soportes, como el pergamino, fueron menos habituales y quedaron reservados a lo que podrían calificarse como ediciones de lujo. Se observa en 150 ejemplares de los 1.000 encargados para la orden de San Bernardo por el monasterio salmantino de Nuestra Señora de Loreto. En el contrato se especificaba lo siguiente:

Yten, obligamos que los pliegos que se nos mandaren y señalaren de los dichos çiento e çinquenta misales y cada uno de [e]llos se inpriman en pergamino, los imprimiremos en el dicho pergamino que sea muy blanco y delgado e bien raspado y adereçado; y se nos ha de pagar a real y medio por pliego de la dicha impresión que en el dicho pergamino ynprimiéremos" 71 .

Las peculiaridades referentes al tipo de letra son objeto de preocupación de aproximadamente uno de cada cuatro contratos y en uno de cada diez enfatizaban que esta fuese nueva. Al igual que sucedía con otras características de la obra, para

${ }_{66}$ Con papel bastardo de esta procedencia tuvo problemas Julio de Junta indicando que le había llegado muy sucio, lleno de motas y agujeros y que no lo podía aprovecharlo para imprimir libros. El monasterio de Nuestra Señora de Loreto exigió a Juan Fernández y Juan Pulman que el papel de marquilla bastardo estuviese limpio, no marcado, ni roto. A. H. P. Sa. P. N. Leg. 4857. 22-VII-1573. Fols. 263-267; Leg. 3209. 31-VIII-1589. Fols. 266-270; Leg. 4870. 13-XI-1589. Fol. 1299 v.

67 A. H. P. Sa. P. N. Leg. 3187. 26-X-1574. Fols. 118-132.

68 A. H. P. Sa. P. N. Leg. 3670. 19-XI-1596. Fols. 778-779; Leg. 5263. 2-XII-1591. Fols. 808-811.

69 A. H. P. Sa. P. N. Leg. 4637. 15-VIII-1586. Fols. 2399-2408.

70 A. H. P. Sa. P. N. Leg. 3188. 24-II-1576. Fols. 294-300.

71 A. H. P. Sa. P. N. Leg. 4870. 13-XI-1589. Fol. 1300 r. 
la tipología de la letra podían tomarse otras impresiones como referente. Los comentarios al Ordenamiento Real del doctor Diego Pérez se debían efectuar con las letras y caracteres utilizados en las leyes de Partida "que Gregorio López agora nuevamente ha ynpreso, con sus señales e divisiones e diferencias de letras que fueren necesarias" 72 . El Tractatus de juramento confirmatorio del licenciado Juan Gutiérrez se habría de componer con la misma letra

...que tiene el libro que está y anda impreso de las Varias resolutiones del ilustrísimo señor don Diego de Covarrubias, obispo de Segovia, presidente del Consejo Real, por manera que sea de aquel tamaño y grueso de letra, y no más, ni menos. Y la letra sea nueva para que salga llena y clara y no cenida; y la tinta, ansí mismo, ha de ser muy buena y fina; y el título de cada capítulo y el de las márgenes altas ha de ser de letra mayúscula; y los sumarios y tablas de letra menuda ${ }^{73}$.

En el caso del misal encargado por el monasterio salmantino de Nuestra Señora de Loreto, los títulos de las misas irían impresos en letra gótica, como el romano, y los principios de los oficios con letras mayores floreadas ${ }^{74}$. Algunos documentos contractuales llegaron a penalizar los retrasos derivados del desgaste de las letras que no se "aderezaban" 75 .

En el caso de las tintas, los calificativos de llena, buena, fina, limpia y clara, delimitan las exigencias de la atención prestada a este aspecto. Tales demandas aparecen en la impresión de las Cartillas editadas para la iglesia vallisoletana ${ }^{76}$; o en las obras de Francisco de Ribera, de Lorenzo Osorio o del licenciado Juan Yánez Parladoiro, autores cuyas obras no fueron de las más demandadas ${ }^{77}$. El doctor Francisco de Ribera - autor del Comentario sobre los doce profetas - hacía un requerimiento similar: "los caracteres estarán siempre bien aderezados para que se señalen bien y en eso nunca haya falta, y la letra baya llena de tinta". Del color de las tintas apenas aparecen noticias, entre ellas se halla la compra que efectuó Matías Gast de "bermellón" en Medina del Campo para los tonos rojos, o la impresión de los misales para la orden de San Bernardo que se realizarían "de color negro y colorado" 78 .

Igualmente se delimitaron otros aspectos de la composición como fueron las ilustraciones o la forma de glosar exigiéndose que se respetaran las columnas y títulos de impresiones previas o se hiciesen conforme a un pliego que estaba en poder del autor; siguiendo el modelo de otras ${ }^{79}$; o que la obra se imprimiese a dos

\footnotetext{
A. H. P. Sa. P. N. Leg. 2934. 17-III-1557. Fol. 362.

A. H. P. Sa. P. N. Leg. 4857. 22-VII-1573. Fols. 263-267.

A. H. P. Sa. P. N. Leg. 4870. 13-XI-1589. Fol. 1300 v.

A. H. P. Sa. P. N. Leg. 4640. 19-I-1587. Fols. 2238-2243.

76 Se imprimirían en letra paradina y cursiva, en papel número dos, siguiendo el modelo de las editadas por Felipe Junta en Burgos. A. H. P. Sa. P. N. Leg. 3202. 18-I-1584. Fols. 185-188 y 9-II-1584. Fol. 196.

77 En la del primero se indicaba que la "impresión ha de ser limpia y clara, que se pueda leer bien". El segundo exigía "tinta buena y bien correcta”. A. H. P. Sa. P. N. Leg. 3209. 19-IX-1589. Concierto con Lorenzo Osorio Barba. Fols. 117-120; Leg. 3212. 11-IX-1590. Fols. 241-247.

78 A. H. P. Sa. P. N. Leg. 3188. 26-III-1576. Fol. 449; Leg. 4870. 13-XI-1589. Fol. 1300 r.

79 En los Comentarios de fray Francisco Zumel, catedrático de Teología de la Universidad salmantina y provincial de la provincia de Andalucía y Castilla la Vieja de la Orden de la Merced, las columnas habrían de ser de la anchura de la Prima Secunda de fray Bartolomé de Medina impresa en 1578. A. H. P. Sa. P. N. Leg. 4641. 10-VI-1588. Fols. 271-272.
} 
columnas ${ }^{80}$. Las especificaciones sobre las figuras que acompañaron al texto suelen ser excepcionales dado que no todas las obras las insertaban. Entre ellas se encuentra el Tratado sobre mathemáticas del bachiller jiennense Juan Pérez de Moya, quien demandaba la inclusión de "çiertas historias de figuras de madera que yo tengo del dicho libro, para que el dicho Juan de Cánoba inprima el dicho libro y después de ynpreso el dicho libro, el dicho Juan de Cánoba me ha de volver las dichas historias de figuras de madera" ${ }^{\prime 1}$.

La designación de correctores concretos no fue objeto de demasiada atención por las partes afectadas, tal vez porque los impresores ya disponían de sus propios profesionales para este trabajo ${ }^{82}$. Esto se puede afirmar, al menos, para alguno de ellos, como se aprecia en el contrato que firmó Lucas de Junta, hijo de venecianos, en 1582 con Alonso González de la Torre, vecino de Salamanca. Este último se encargaría de corregir todas las obras que imprimiese Lucas a cambio de real y medio por pliego

...como sea de negro de letra que dice de le[c]tura e mayor y si fuere de letra menor, que es mayor trabajo, el dicho Lucas se lo ha de satisfaçer en libros o en otra cosa fuera de cuenta. Si fuere de colorado y negro le ha de pagar por cada pliego de corrección al respecto de tres ducados por cada prensa cada mes.

El impresor no le podría abonar todo el salario en libros, sino solamente el equivalente a una prensa y los elegiría el corrector dándoselos al precio de la tasa - al igual que a otros libreros - ${ }^{83}$. En algunos casos se estableció también un corrector a elección del autor o se exigieron determinadas cualidades para el mismo. Don Gaspar de Zúñiga, obispo de Segovia, fue uno de los pocos que determinó poner un segundo corrector, además del que ya tenía Andrea de Portonaris, "otra persona de su mano, a costa de dichas iglesias [de Segovia, a donde iban destinadas las obras litúrgicas], que torne a rever las pruebas e las apruebe e firme de su mano para que la obra baya más perfeta". Sólo bajo el cumplimiento de esta condición el impresor quedaría exonerado de cualquier falta. En caso contrario "las corregir[í]a, sea de falta de palabras, agora de renglones o de açentos, o ditongos o borrones" ${ }^{84}$.

Algunos contratos establecieron que las pruebas se entregasen a diario para que se corrigiesen e imprimiese la obra en el periodo establecido. En la del doctor Francisco de Ribera se señalaba que se enviasen al colegio de los jesuitas, donde residía, y se le concedería una hora para corregir "y en este término se pueda añadir o quitar del pliego algún renglón o renglones, y si más tiempo las tuviere sean a

80 Esto último se acordó en la impresión del Comentario sobre los doce profetas menores del doctor Francisco de Ribera. La de fray Francisco Zumel se haría "a columna partida y de sesenta y cuatro renglones cada columna”. A. H. P. Sa. P. N. Leg. 4640. 1587. Fols. 2238-2243; Leg. 4853. 1-X-1567. Fols. 348-350; Leg. 4646. 2-V-1589. 2454-2457. Véase, S. GARZA MERINO, "El Tratado de Mathemáticas de Juan Pérez de Moya en la imprenta", en P. M. CÁTEDRA y Mª L. LÓPEZ-VIDRIERO, Op. cit., I, pp. 435-462.

81 A. H. P. Sa. P. N. Leg. 4853. 9-VI-1567. Fols. 346-347.

82 El contrato para la impresión de la obra del licenciado Diego Cantera estipulaba que el corrector fuese a costa del impresor y se obligase a que estuviese "muy bien correxido, principalmente en la ortografía". Véase, A. H. P. Sa. P. N. Leg. 4646. 13-I-1589. Fols. 2367-2371. Leg. 3199. 11-III-1583. Fol. 406.

83 El corrector ya llevaba tiempo corrigiendo obras para Lucas, entre ellas las de Garcilaso, Juan de Mena, fray Luis de León y las de Antonio Gómez, las cuales estaba imprimiendo en ese momento. A. H. P. Sa. P. N. Leg. 4631. 13-III-1582. Fols. 2001-2002.

84 A. H. P. Sa. P. N. Leg. 3874. 10-VII-1556. Fols. 234-239. 
costa del autor" $" 85$. Algunos solicitaron un corrector que fuese experto en la materia sobre la que versaba la obra, como el licenciado placentino Juan Gutiérrez quien demandó para su Tractatus de juramento confirmatorio que se designase un

...jurista, buen latino y ortógrafo, que corrija el libro antes que se imprima y como se fuere imprimiendo podrá enmendar los herrores que en él hoviere en la impresión, así en el latín como en la ortografía, por manera que lo que se imprimiere para hazer los dichos cuerpos de libros ha de ser y quedar muy corregido, limpio, concertado y con la orden y diferencias de letras y distinción de renglones que otros libros de Derecho se suelen imprimir, y especialmente el que está dicho de Las Varias del dicho señor presidente [del Consejo Real, don Diego de Covarrubias $]^{86}$.

Ante tales prevenciones, la aparición de cualquier errata encontrada debería correr a costa de la imprenta. La comisión de estas faltas estuvo probablemente ligada a los medios técnicos o a la formación de los profesionales, pero también al volumen de trabajo y al tiempo en el que debía desarrollarse la impresión. En algún acuerdo se concertó que las pruebas tendrían que quedar en manos del autor pena de una fuerte multa, probablemente para evitar venderlas o efectuar nuevas ediciones a través de ellas ${ }^{87}$.

Tanto lo que respecta al número de volúmenes de la edición como la duración del proceso tipográfico, constituyeron facetas, especialmente la primera, objeto de especial atención de las cláusulas contractuales. Al menos en tres de cada cuatro contratos se fija el número de obras a imprimir. La cifra osciló en Salamanca desde las 400 de la impresión del Comentario sobre la Primera Parte de Santo Tomás, de Francisco Zumel, a las 2.300 Biblias de Vatablo o las 50.000 cartillas encargadas por la iglesia vallisoletana. La impresión moda fue de 1.000 ejemplares, aunque la de 1.500 tuvo una demanda casi $\operatorname{similar}^{88}$. La resma de papel impresa se pagó a menor precio cuanto mayor era el volumen de ejemplares a imprimir ${ }^{89}$.

La cantidad pactada en los contratos podía tener cierta flexibilidad. En el acuerdo entre el impresor Domingo Portonaris y su mujer Beatriz de Cuéllar y Tomás Tobar, fiscal del rey, para la tercera edición de la Glosa de las Siete Partidas del licenciado Gregorio López, suegro de Tomás, se indica que "no se imprimirá más número, salvo los pliegos que demás de los 1.500 se acostumbran a echar en semejantes impresiones y si se echa de más ha de ser veinticinco" los cuales quedarían en manos del autor abonándolos a los impresores. Además, se podría editar otro ejemplar para el corrector o correctores y los dos que se daban habitualmente a los

85 A. H. P. Sa. P. N. Leg. 4640. 19-I-1587. Fols. 2238-2243.

86 A. H. P. Sa. P. N. Leg. 4857. 22-VII-1573. Fols. 263-267.

87 En la impresión de la Glosa sobre las Siete Partidas se fijó en 500 ducados. A. H. P. Sa. P. N. Leg. 3186. 1574. Fols. 523-530.

88 En Francia osciló entre 300 y 2.250. Lo más habitual es que se estableciese entre 600 y 1.250 ejemplares para acomodarse al ritmo de trabajo cotidiano. H.-J. MARTIN y R. CHARTIER, Histoire de l'édition française. Le libre conquérant du Moyen Age au milieu du XVIIe siècle, I, Paris, 1982, p. 282.

89 Véase, A. H. P. Sa. P. N. Leg. 3667. 1590. Venta de prensa de Octaviano Parente a Diego Cusío y acuerdo de impresión. Fols. 321-324. 
oficiales de la prensa — "la capilla"— ${ }^{90}$. Alejandro de Cánova compuso dos breviarios de más de los 60 encargados por don Juan de San Millán, obispo de León, junto a otros mil pliegos y "las sobras de dicho breviario", todo lo cual se vendió al prelado a 4 maravedíes el pliego ${ }^{91}$. Sólo excepcionalmente, como sucedió con las Aserciones de fray Antonio Rubio, se dejaba la posibilidad al impresor para que rebajase la cifra pactada ${ }^{92}$.

Por otro lado, el hecho de que algunos de los autores exigiesen que los ejemplares impresos fuesen firmados de su nombre o de su apoderado, resulta significativo del posible fraude que podría darse en este aspecto ${ }^{93}$. En el acuerdo sobre la impresión de la Glosa de las Siete Partidas del licenciado Gregorio López, las partes se remitieron a la ley que castigaba con 50.000 maravedíes de multa por cada ejemplar que apareciese sin rubricar; en el de Los doce profetas menores del doctor Francisco Ribera se elevaba esta cifra al doble o a la perdida de los libros impresos de más ${ }^{94}$. En otros casos se redujo la cuantía demandada, como en el de la impresión de los Comentarios sobre Galeno del licenciado Luis de Lemos, portugués. Se delimitó en 13.500 maravedíes por cada ejemplar que no estuviese rubricado por su apoderado fray Juan Ramírez, rector del Colegio del Rey de Salamanca ${ }^{95}$. La misma sensación de desconfianza se percibe en cláusulas del siguiente estilo: "y se le encarga la conciencia [al impresor] que no quede con ningún libro en casa", síntoma de que no se cumplía siempre lo pactado al respecto ${ }^{96}$.

El tiempo asignado para las impresiones y el número de prensas puestas a trabajar osciló de unas obras a otras, aunque no siempre estuvo en relación con el volumen de ejemplares requeridos. El tiempo mínimo establecido varió desde los dos meses y medio - para los 1.000 ejemplares de Pina de Rosas - hasta los veinte meses - que se concedieron para los 1.500 ejemplares de la Glosa de las Siete Partidas del licenciado Gregorio López- ${ }^{97}$. Lo más habitual era que se estableciesen entre seis y ocho meses para la finalización de las impresiones. Algunos de los documentos fijaron incluso un día concreto para iniciar la tirada penalizando al autor o glosador de la obra si no tenía el original dispuesto para la fecha ${ }^{98}$. En otras

90 De las Reglas del Derecho del doctor Pedro Dueñas, Andrea de Portonaris imprimiría 1.000 volúmenes, "diez más o menos". Lo mismo se estipulaba con Diálogos de la jornada de Alemania, de Diego Núñez de Alba. En el caso de los Fragmentos mathemáticos del bachiller Juan Pérez de Moya, o del Oficio Defuntorum de don Gonzalo de Solórzano, la oscilación permitida se estableció en 20 libros. En los Comentarios sobre la primera parte de Santo Tomás de fray Domingo Báñez se elevó hasta 25. A. H. P. Sa. P. N. Leg. 3186. 1574. Fols. 523-530; Leg. 4073. 29-XII-1553. Fols. 955-956; Leg. 4073. 24-IX-1552. Fol. 957; Leg. 4161. $28-I X-1564$. Fols. 567-568; Leg. 4853. 9-VI-1567. Fols. 346-347; Leg. 2947. 27-X-1571. Fols. 686-687; Leg. 3201. 16-IX1583. Fols. 133-135.

91 A. H. P. Sa. P. N. Leg. 4161. 28-IX-1564. Fols. 567-568.

92 A. H. P. Sa. P. N. Leg. 4853. 1-X-1567. Fols. 348-350.

93 Para el control del número de ejemplares y evitar fraudes, además de la firma del autor o apoderado, se podía efectuar una señal demandada por este. Véase, C. PÉREZ PASTOR, Op. cit., p. 252.

94 A. H. P. Sa. P. N. Leg. 4640. 28-I-1587. Fols. 1859-1860; Leg. 5247. 17-V-1585. Fol. 1420.

95 A. H. P. Sa. P. N. Leg. 4625. 9-V-1580. Fols. 1735-1736.

96 A. H. P. Sa. P. N. Leg. 4857. 22-VII-1573. Fols. 263-267.

97 A. H. P. Sa. Leg. 3187. 29-X-1574. Fols. 141-144.

98 El Capítulo de Corregidores del doctor Pedro Núñez de Avendaño y el Diccionario deberían estar acabados en un plazo de seis meses, pena de una fuerte multa de 600 ducados. En algún contrato se señala que la finalización en la mayor brevedad de tiempo posible no era sólo una cuestión "de provecho" para el autor, sino también para el impresor. A. H. P. Sa. P. N. Leg. 3180. 23-XI-1580. 536-537; Leg. 3181. 28-XII-1571. Fol. 41-42; Leg. 3651. 23-V-1553. Fols. 183-184; Leg. 4857. 22-VII-1573. Fols. 263-267. 
ocasiones se estipulaba un número de pliegos diarios a realizar por las prensas ${ }^{99} . \mathrm{Si}$ había retrasos por culpa de los autores la multa ocasionada por estas dilaciones, como ya se ha señalado, podía ir destinada tanto a los editores como a los oficiales de la imprenta ${ }^{100}$.

Para evitarla se solía asignar un número de prensas a la impresión, un volumen de pliegos a realizarse diariamente y la exigencia de que el proceso se efectuase "sin alzar la mano" o "hasta que se acab[as]e la gera", es decir, sin interrumpir el trabajo de la prensa para introducir otra obra ${ }^{101}$. En algún caso esta exposición se supervisó por parte de una persona encargada por el autor. El doctor Juan Nieto, colegial de Salamanca, se encargó de inspeccionar diariamente los trabajos sobre la obra Questiones Criminales del licenciado e inquisidor Diego de la Cantera, a cargo del flamenco Cornelio Bonart - Cornelis Boonart- ${ }^{102}$. Otros autores incluso requirieron que la impresión se hiciese "como obra principal y no accesoria a otra", penalizando gravemente cualquier retraso ${ }^{103}$. Destaca entre ellas la sanción fijada en el contrato entre el licenciado Luis Lemos y el citado Cornelio Bonart quien pagaría 1.000 maravedíes diarios por cada día que transcurriese sin labor y no diera un pliego impreso ${ }^{104}$. En cualquier caso, el volumen de trabajo requerido nunca sobrepasó la exigencia de más de dos prensas en funcionamiento salvo para la impresión del Nuevo Rezado para el cual hubo de recurrirse a varios talleres tipográficos.

De las últimas fases de la confección de la obra, caso de la encuadernación, los contratos no suelen adentrarse en este tipo de cuestiones. Desconocemos en este sentido si todos los libros impresos acabaron encuadernados o no, o si lo hicieron en la ciudad tormesina o fuera de ella ${ }^{105}$. Sólo hacen referencia a este aspecto cuando se trata de algún libro para el autor que probablemente iría destinado a algún tipo de regalo o a la persona a la que iba dedicada la obra, como sucedió con un ejemplar del Capítulo de Corregidores de Avilés el cual tenía que entregarse "encuadernado dorado"106.

La misma carencia de datos hallamos en todo lo relativo al empaquetado y distribución de los volúmenes impresos. Algunos de los mercaderes de libros -

99 Para la Glosa de las Siete Partidas dos resmas diarias. A. H. P. Sa. P. N. Leg. 3186. 1573. Fols. 529-530.

100 En el concierto para la impresión del Ordenamiento Real se estipuló en 50 ducados. A. H. P. Sa. P. N. Leg. 2934. 17-III-1557.

101 La glosa a las Siete Partidas del licenciado Gregorio López se debería iniciar en un plazo máximo de ocho meses y una vez comenzado el proceso de impresión no sobrepasaría el año, penalizándose con la elevada cifra de 2.000 ducados cualquier dilación. A. H. P. Sa. P. N. Leg. 3186. 1574. Fols. 523-530; Leg. 4640. 19-I1587. Fols. 2238-2243.

102 A. H. P. Sa. P. N. Leg. 4646. 13-I-1589. Fols. 2367-2371.

103 Sonia Garza interpreta esta exigencia de no aceptar otro trabajo hasta que no se acabara el recién admitido - al margen de la aceptación de otros encargos menores - como una forma de organización de una empresa en torno a un proyecto. La realidad es que tal exigencia no siempre afectó a la totalidad de las prensas con las que contaba el impresor. S. GARZA MERINO, "La cuenta del original", en F. RICO, Imprenta y crítica textual en el Siglo de Oro, Valladolid, 2000, p. 73.

104 La penalización iría destinada a fines benéficos: la mitad para el Hospital de Santa María la Blanca y la otra mitad para el Hospital de San Bernardo de Salamanca, decisión que no es de extrañar si tenemos en cuenta la estrecha relación del autor con el mundo de la medicina. A. H. P. Sa. P. N. Leg. 4625. 9-V-1580. Fols. 17351736.

105 Entre las encuadernaciones realizadas en la ciudad está la de la obra de Héctor Pinto llevada a cabo por el encuadernador, también portugués, Juan Rodríguez. A. H. P. Sa. P. N. Leg. 4628. 14-IX-1581. Fol. 2206.

106 A. H. P. Sa. P. N. Leg. 3189. 13-VII-1576. Fols. 317-318. 
Alejandro de Cánova o Simón Borgoñón, entre otros - recurrieron a vecinos del valle de Cabuérniga, concretamente a los de Los Tojos, para la provisión de diferentes tipos de tablas con las que mandaban construir las cajas en las que se embalaban los ejemplares ${ }^{107}$. Solían transportarse también en "arpilleras" - probablemente sacos fabricados con este material - cobrándose aparte los cordeles y sogas de esparto que se necesitaban para liar las cargas ${ }^{108}$. En los contratos analizados, sólo el relativo a la Glosa de las Siete Partidas del licenciado Gregorio López fijó parte de su atención en este sentido. Deberían ser trasladados de manera que fuesen "bien puestos y atados con sus sogas o cordeles y papelones a los cantos, y en cada bala no podrá ir más de tan solamente seis cuerpos". Serían enviados a la casa del yerno del autor - Tomás de Tobar, residente en Valladolid, quien negoció la impresión - manteniéndolos bien tratados y guardados hasta la entrega ${ }^{109}$.

\section{Consideraciones finales}

Los contratos de edición, como hemos podido apreciar, sólo nos pueden proporcionar una instantánea de lo que fue la edición libraría del siglo XVI en Salamanca, así como intuir simplemente algunos de los posibles problemas a los que se enfrentaron autores e impresores en función de las cláusulas penales establecidas - fraudes en el número de libros impresos, mala calidad de letra o tinta de algunas impresiones, o deterioros en la conservación y transporte de la obra, entre otros-. No obstante, nos sirven para abrir el camino a estudios posteriores donde se contrasten los aspectos establecidos en las cláusulas contractuales (tipo de papel, de letra, tintas, corrección de erratas, marcas, etc.) con los resultados de la obra final para calibrar el alcance del cumplimiento de tales acuerdos.

Por otro lado, será necesario recurrir a otros documentos realizados ante los escribanos públicos o de carácter judicial para poder percibir de una manera más amplia las dificultades que atravesó la impresión del libro o conocer otros acuerdos firmados de los que no se han conservado originales. Diferentes escrituras notariales, al margen de las reflejadas en el anexo, dejan plasmados múltiples acuerdos sobre adquisiciones de derechos de autor, delegaciones de poderes para lograr licencias de impresión ante el Consejo Real o negociar ediciones o pagarlas ${ }^{110}$. Las de obligación e hipoteca nos informan sobre los embargos realizados a los impresores ante sus dificultades económicas; los procesos judiciales —en el caso de Salamanca los elevados a la Chancillería de Valladolid dado que han desaparecido la mayoría de los incoados en primera instancia-, abundan sobre temas financieros,

107 En el contrato se decía que "dicha tabla ha de ser de marca mayor y de marquilla grande y de misal grande y de pliego entero y de cuarto de marquilla y de madera de haya buena, que sea de dar y de tomar, bien labrada, y grosezuelas tales que sean a su contento". A. H. P. Sa. P. N. Leg. 2937. 28-VI-1560. Fol. 618.

108 A. H. P. Sa. P. N. Leg. 4161. 28-IX-1564. Fols. 567-568.

109 A. H. P. Sa. P. N. Leg. 3186. 1574. Fols. 523-530.

110 A través de una carta de pago de 1564, a la que ya hemos aludido, se nos informa de cómo Alejandro de Cánova imprimió 600 breviarios para el Obispo de León a 320 maravedíes cada uno. Otorgó también poderes para imprimir misales grandes y pequeños y manuales para los obispados de Oviedo y León en 1571, de los que no hemos hallado los contratos originales. A. H. P. Sa. P. N. Leg. 4073. 6-I-1552. Fols. 74-75 y 12-I1552. Fols. 127-128; Leg. 4161 28-IX-1564. Fols. 567-568; Leg. 4855. 17-VII-1571. Fols. 600-601 y 603604. 
sobre la competencia entre los impresores a la hora de interesarse varios de ellos por la edición de una misma obra ${ }^{111}$, sobre ventas de obras sin tasa o licencia ${ }^{112}$, o sobre incumplimientos de los contratos de impresión para que se devolviese el dinero a alguna de las partes ${ }^{113}$; y los considerados documentos infra o extrajudiciales establecen acuerdos ante estas confrontaciones ${ }^{114}$. Al margen de las carencias apuntadas, los documentos contractuales tampoco nos permiten apreciar tendencias en cuanto a autorías o temáticas de obras publicadas dado que la mayoría de las impresas carecieron de una materialización contractual ante un escribano público, se han perdido los originales o simplemente se realizaron de manera verbal.

En lo que respecta a los aspectos formales de los contratos de impresión, aunque mantuvieron unas características comunes, no siguieron unas pautas estrictamente uniformes. Variaron en la amplitud y número de sus cláusulas incluyendo algunos de los parámetros que aconsejaban los expertos de la época - como los de Juan Vázquez de Mármol que ejerció de corrector del Consejo de Castilla - referentes a plazos de impresión, cantidad, tipo de papel, de letra, corrección de pruebas, exclusividad de la edición y tasas, así como otros no señalados por él referentes a la financiación, encuadernación de determinados ejemplares, tintas, ilustraciones o transporte que aparecen reflejados en los documentos ${ }^{115}$.

Los acuerdos conservados en Salamanca responden fundamentalmente a personajes de carácter religioso o con titulación universitaria. En el caso de los autores pertenecientes a las órdenes religiosas se observa una primacía de la Orden de Predicadores, atendiendo al número de publicaciones, y a continuación de la Orden de Frailes Menores, al igual que sucedió en Barcelona ${ }^{116}$. Los libros litúrgicos y de carácter espiritual fueron en mayor medida financiados por los prelados o sus autores. Predominó la impresión en latín para los libros de derecho, para los de carácter litúrgico o los religiosos; mientras que el castellano fue empleado en mayor medida para los de carácter devocional, especialmente los de fray Luis de Granada, por los que los libreros e impresores mostraron gran interés ${ }^{117}$. Entre los contratos aparecen algunos de los autores que los bachilleres de la época consideraban imprescin-

111 Este tipo de letra se había empleado también en otras obras —Suma de los Concilios, Vocabulario Eclesiástico, La Odisea de Homero, Medina de Penitençie y en la mitad de las Sumulas- A. H. P. Sa. P. N. Leg. 3650. 24-III-1550. Fols. 744-786.

112 Véase, J. GARCÍA ORO y Ma J. PORTELA SILVA, La Monarquía y los libros en el siglo de Oro, Alcalá de Henares, 2003, p. 60.

113 A. R. Ch. Va. Pleitos Civiles. Pérez Alonso (F). Caja 301,6. 1531-1534; A. H. P. Sa. P. N. Leg. 3188. 16-II1575. Fols. 238-239.

114 La parte desobediente pagaría 40 ducados para el Hospital de pobres de Santa María la Blanca y 60 ducados para la Cámara Real. A. H. P. Sa. P. N. Leg. 5079. 19-XII-1578. Fols. 1162-1165.

115 Sobre los puntos a tener en cuenta en las condiciones véase, Fernando J. BOUZA ÁLVAREZ, Del escribano a la biblioteca. La civilización escrita europea en la Alta Edad Moderna (siglos XV-XVII), Madrid, 1997, p. 64.

116 J. L. BERTRÁN y C. BLANCO FERNÁNDEZ, "La imprenta y el libro religioso en la Cataluña de los siglos XVI y XVII", en Homenaje a don Antonio Dominguez Ortiz, I. Granada, 2008, p. 97.

117 Fray Luis de Granada junto con Benito Arias Montano constituyeron los dos autores más importantes del fondo editorial de Cristóbal Plantino en Amberes. Parte de sus trabajos tipográficos eran reimpresiones de las ediciones originales del fraile en Lisboa y Salamanca. Frans M.A. Robben califica la Guía de Pecadores y Libro de la oración y meditación como dos best-sellers de gran difusión en Europa. F. M.A. ROBBEN, "Juan Pulman, librero y agente de la oficina plantiana en Salamanca”, en H. TROMP y P. PEIRA (coords.), Simposio Internacional sobre Cristóbal Plantino, Madrid, 1991, p. 10. 
dibles — "sin los que no se puede pasar"- caso del Dr. Pedro Núñez de Avendaño, el licenciado Gregorio López o don Diego de Covarrubias y Leyba ${ }^{118}$.

Las prácticas editoriales salamantinas manifiestan algunos paralelismos con las de otras zonas para la misma época. Al igual que en París, se observa una mayor compensación en ejemplares a los autores por su trabajo de parte de los editores que mediante cantidades monetarias - prácticamente en seis de cada diez casos; en dos de cada diez percibieron ejemplares y dinero- ${ }^{119}$. Las tiradas más habituales, de 1.000 y 1.500 cuerpos, fueron también frecuentes en las imprentas de Medina del Campo o en las de Toledo ${ }^{120}$.

A diferencia de lo que estaba sucediendo en otras ciudades de la Corona castellana - caso de Sevilla - la actividad en la edición del libro en Salamanca no nos permite pensar que se estuviese dando un proceso de descapitalización en este sector. La financiación de las obras de fray Luis de Granada, de la Biblia de Vatablo o la edición del Nuevo Rezado, además de las obras citadas en este trabajo, ponen de relieve la existencia de una actividad tipográfica continuada - tal vez más intensa durante las décadas de los 50, 70 y 80 del siglo XVI - que encontraba alternativas en unos impresores cuando otros fallecían o decaían ${ }^{121}$. El encargo de la impresión del Nuevo Rezado puede constituir un dato significativo de la mejora de la imprenta salmantina si tenemos en cuenta que a principios de siglo su cabildo catedralicio mandó imprimir su breviario en Venecia, el primer centro tipográfico editorial italiano a larga distancia de Florencia, y siete décadas después Salamanca estaba compitiendo con aquella ciudad en la edición de este tipo de obras litúrgicas ${ }^{122}$.

\section{Anexo}

Contratos de impresión establecidos por los impresores extranjeros en Salamanca en el siglo XVI. Fuente: Protocolos Notariales del A. H. P. Sa. (elaboración propia).

118 Á. WERUAGA PRIETO, "Los universitarios y el libro en la Salamanca clásica (ss. XVI-XVIII)", en Fuentes, archivos y bibliotecas para una historia de las universidades hispánicas, Miscelánea Alfonso IX, 2014, p. 292.

119 R. CHARTIER, El orden de los libros..., Op. cit., p. 58.

120 En Barcelona en la primera mitad del siglo XVIII en llegaron a los 1.200, dependiendo del carácter de la obra. En Valencia oscilaron entre los 300 y los 2.000. Berger señala que, aunque las tiradas de 1.000 ejemplares no fueron raras, eran esencialmente obras en castellano y de uso corriente entre la masa de lectores. Véase, C. PÉREZ PASTOR, Op. cit., p. 138; J. T. VELASCO SÁNCHEZ, "La imprenta en Medina del Campo en el siglo XVI", en Isabel I y la imprenta, consecuencias materiales en el mundo cultural de esta revolución tecnológica, Madrid, 2004, p. 4; J. RUBIÓ Y BALAGUER, Llibreters i impressors a la Corona d'Aragó, Barcelona, 1993, p. 157; Ph. BERGER, Libro y lectura en la Valencia del Renacimiento (1), Valencia, 1987, pp. 129 y 131; H. RODRÍGUEZ DE GRACIA, Op. cit., pp. 63 y 72.

121 C. A. GONZÁLEZ SÁNCHEZ y Na. MAILLARD ÁLVAREZ, Orbe tipográfico. El mercado del libro den la Sevilla de la segunda mitad del siglo XVI, Gijón, 2003 p. 21.

122 En 1502 el cabildo encargó al milanés Bernardino de Castronovo y a Antonio de Barreda la impresión a molde en la ciudad de Venecia de 100 breviarios "en buen papel, blanco, que no se esparza y de muy buena tinta y muy negra y del tamaño de la letra y de aquella grandeza e grosura de letra e tamaño de marca e de muy buen bermellón, fino y colorado", encuadernados en cordobán. Archivo Catedralicio de Salamanca. Caja

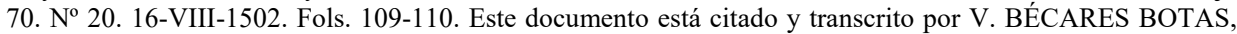
"Los agentes del libro incunable salmantino (1483-1510)", Titivillus, 2, (2016), pp. 94-98; M. SANTORO, Storia del libro italiano. Milano, 2000, pp. 108-109. 


\begin{tabular}{|c|c|c|c|c|}
\hline $\begin{array}{l}\text { Autor, glosador } \\
\text { o compilador }\end{array}$ & $\begin{array}{l}\text { Obra (según se cita } \\
\text { en los documentos) }\end{array}$ & Editor/ impresor & Ejemplares & Año \\
\hline $\begin{array}{l}\text { Fray Alonso de } \\
\text { Castro (O. F. M.) }\end{array}$ & $\begin{array}{l}\text { De iusta hereticorum } \\
\text { puniçione }^{123}\end{array}$ & $\begin{array}{l}\text { Alejandro de } \\
\text { Cánova }\end{array}$ & & 1547 \\
\hline $\begin{array}{l}\text { Diego Núñez de } \\
\text { Alba }\end{array}$ & $\begin{array}{l}\text { Diálogos de la jornada } \\
\text { de Alemania }\end{array}$ & $\begin{array}{l}\text { Andrea de } \\
\text { Portonaris }\end{array}$ & 1000 & 1552 \\
\hline $\begin{array}{l}\text { Dr. Pedro Núñez } \\
\text { de Avendaño }\end{array}$ & $\begin{array}{l}\text { Capítulos de } \\
\text { Corregidores }\end{array}$ & $\begin{array}{l}\text { Alejandro de } \\
\text { Cánova }\end{array}$ & & 1553 \\
\hline $\begin{array}{l}\text { Dr. Pedro Núñez } \\
\text { de Avendaño }\end{array}$ & $\begin{array}{l}\text { Diccionario español } \\
\text { sobre leyes de } \\
\text { Partidas }^{125} \text {. }\end{array}$ & $\begin{array}{l}\text { Alejandro de } \\
\text { Cánova }\end{array}$ & & 1553 \\
\hline \multirow[t]{6}{*}{$\begin{array}{l}\text { Doctor Pedro de } \\
\text { Dueñas }\end{array}$} & Reglas de Derecho ${ }^{126}$ & $\begin{array}{l}\text { Andrea de } \\
\text { Portonaris }\end{array}$ & 1000 & 1553 \\
\hline & Breviarios & $\begin{array}{l}\text { Andrea de } \\
\text { Portonaris }\end{array}$ & 450 & 1556 \\
\hline & Misales & $\begin{array}{l}\text { Andrea de } \\
\text { Portonaris }\end{array}$ & 1000 & 1556 \\
\hline & Pasionarios & $\begin{array}{l}\text { Andrea de } \\
\text { Portonaris }\end{array}$ & 750 & 1556 \\
\hline & Manuales & $\begin{array}{l}\text { Andrea de } \\
\text { Portonaris }\end{array}$ & 750 & 1556 \\
\hline & Procesionarios & $\begin{array}{l}\text { Andrea de } \\
\text { Portonaris }\end{array}$ & 1000 & 1556 \\
\hline $\begin{array}{l}\text { Dr. Diego Pérez } \\
\text { (Catedrático) }\end{array}$ & $\begin{array}{l}\text { Ordenamiento Real } \\
\text { (glosado) }\end{array}$ & $\begin{array}{l}\text { Juan María de } \\
\text { Terranova y } \\
\text { Jacobo de Liarcari }\end{array}$ & & 1557 \\
\hline $\begin{array}{l}\text { Fray Antonio } \\
\text { Rubio (O. F. M.) }\end{array}$ & $\begin{array}{l}\text { Assertionum } \\
\text { catholicarum aduersus } \\
\text { Erasmi }_{\text {Roterodami }}{ }^{127}\end{array}$ & Juan de Cánova & 1000 & 1567 \\
\hline $\begin{array}{l}\text { Bachiller Juan } \\
\text { Pérez de Moya }\end{array}$ & $\begin{array}{l}\text { Fragmentos } \\
\text { Mathemáticos }\end{array}$ & Juan de Cánova & 1500 & 1567 \\
\hline $\begin{array}{l}\text { D. Gonzalo de } \\
\text { Solórzano } \\
\text { (obispo) }\end{array}$ & Oficio defuntorum & $\begin{array}{l}\text { Alejandro de } \\
\text { Cánova }\end{array}$ & 700 & 1571 \\
\hline Dr. Diego Pérez & $\begin{array}{l}\text { Glosa sobre la segunda } \\
\text { parte del } \\
\text { Ordenamiento Real }{ }^{129}\end{array}$ & $\begin{array}{l}\text { Vicente de } \\
\text { Portonaris }\end{array}$ & 1231 & 1573 \\
\hline $\begin{array}{l}\text { Fray Luis de } \\
\text { Granada (O. P.) }\end{array}$ & $\begin{array}{l}\text { Libro de la Oración y } \\
\text { meditación }^{130}\end{array}$ & $\begin{array}{l}\text { Domingo de } \\
\text { Portonaris Ursinos } \\
\end{array}$ & & 1573 \\
\hline
\end{tabular}

123 Existe una edición de Juan de Junta de 1548, De Iusta haereticorum punitione. L. RUIZ FIDALGO, Op. cit., I, p. 366.

124 Ibídem, p. 424.

125 Ambas obras se insertan en el volumen De exequendis mandatis Regum Hispaniae, la segunda bajo el título Dictionarium Hispanum. 1554. Ibidem, p. 441.

126 Regularum utriusque iuris. Liber primus. 1554. Ibidem, p. 437.

127 Assertionum catholicarum aduersus Erasmi errores. Libri novem. 1568. Ibidem, tomo II, p. 631.

128 1568. Ibidem, p. 619.

129 Comentaria in libros ordinationum regni Castellae. Secunda editio. 1574. Ibidem, p. 786-787.

130 Ibidem, p. 757. 


\begin{tabular}{|c|c|c|c|c|}
\hline $\begin{array}{l}\text { Fray Luis de } \\
\text { Granada } \\
\text { (O. P.) }\end{array}$ & Guía de Pecadores $^{131}$ & $\begin{array}{l}\text { Domingo de } \\
\text { Portonaris Ursinos }\end{array}$ & & 1573 \\
\hline $\begin{array}{l}\text { Ldo. Gregorio } \\
\text { López } \\
\left(\mathrm{C}^{\mathrm{o}} \text { Indias }\right)\end{array}$ & $\begin{array}{l}\text { Glosa sobre las Siete } \\
\left.\text { Partidas ( } 3^{\text {a }} \text { edición }\right)\end{array}$ & $\begin{array}{l}\text { Domingo de } \\
\text { Portonaris Ursinos }\end{array}$ & 1500 & 1574 \\
\hline $\begin{array}{l}\text { D. Diego de } \\
\text { Covarrubias y } \\
\text { Leyba (obispo) }\end{array}$ & No se indica $^{132}$ & $\begin{array}{l}\text { Domingo de } \\
\text { Portonaris Ursinos }\end{array}$ & 1250 & 1575 \\
\hline $\begin{array}{l}\text { Dr. Francisco de } \\
\text { Avilés }\end{array}$ & $\begin{array}{l}\text { Sobre el capítulo de } \\
\text { Corregidores }\end{array}$ & $\begin{array}{l}\text { Vicente de } \\
\text { Portonaris }\end{array}$ & 1500 & 1576 \\
\hline $\begin{array}{l}\text { Fray Bartolomé } \\
\text { de Medina } \\
\text { (catedrático) }\end{array}$ & $\begin{array}{l}\text { Breve Instrucción } \\
\text { confesores }^{133}\end{array}$ & $\begin{array}{l}\text { Lucrecia de Junta, } \\
\text { Cornelio Bonart y } \\
\text { Diego de Robles }\end{array}$ & & 1579 \\
\hline $\begin{array}{l}\text { Ldo. Luis de } \\
\text { Lemos }\end{array}$ & $\begin{array}{l}\text { Commentaria in } \\
\text { Galenum }^{134}\end{array}$ & Cornelio Bonart & 500 & 1580 \\
\hline \multirow[t]{3}{*}{$\begin{array}{l}\text { Fray Domingo } \\
\text { Báñez (O. P. } \\
\text { catedrático) }\end{array}$} & $\begin{array}{l}\text { Comentarios sobre la } \\
\text { primera parte de Santo } \\
\text { Tomás }\end{array}$ & Cornelio Bonart & 750 & 1583 \\
\hline & Biblia de Vatablo ${ }^{135}$ & $\begin{array}{l}\text { Gaspar de } \\
\text { Portonaris }\end{array}$ & 2300 & 1583 \\
\hline & Cartillas & Lucas de Junta & 50000 & 1584 \\
\hline $\begin{array}{l}\text { Fray Damián } \\
\text { Díez (O. P.) }\end{array}$ & $\begin{array}{l}\text { Elenco de las obras en } \\
\text { romançe del muy } \\
\text { reverendo padre fray } \\
\text { Luis de Granada }\end{array}$ & Cornelio Bonart & & 1584 \\
\hline $\begin{array}{l}\text { Dr. Francisco de } \\
\text { Ribera }\end{array}$ & $\begin{array}{l}\text { Comentario sobre los } \\
\text { doce profetas } \\
\text { menores }^{136}\end{array}$ & Julio de Junta & 1500 & 1587 \\
\hline $\begin{array}{l}\text { Ldo. Diego de } \\
\text { Tapia (abad) }\end{array}$ & $\begin{array}{l}\text { Dialogus de triplici } \\
\text { bono }{ }^{137}\end{array}$ & Cornelio Bonart & 1525 & 1587 \\
\hline $\begin{array}{l}\text { Fray Francisco } \\
\text { Zumel (O. de M.) }\end{array}$ & $\begin{array}{l}\text { Comentario sobre la } \\
\text { Primera Parte de Santo } \\
\text { Tomás }{ }^{138}\end{array}$ & Cornelio Bonart & 400 & 1588 \\
\hline
\end{tabular}

131 Ibidem, p. 756.

132 Probablemente se esté refiriendo a la Opera omnia impresa entre 1576-1578. Ibídem, p. 807-808.

133 Breve instructión de cómo se ha de administrar el sacramento de la penitencia. Herederos de Matías Gast. Ibídem, p. 867. A. H. P. Sa. P. N. Leg. 3190. 13-VI-1579. Fols. 775-779 y 784-785.

134 Se habían impreso siete volúmenes y se editaban, bajo este contrato, los cinco que faltaban hasta un total de doce con los que contaba la obra. Ignoramos a qué se debió esta fragmentación. Según María Marsá, era habitual en España, ante la escasa capacidad de los talleres tipográficos, dar a imprimir alguno de los tomos de una obra que tenía múltiples volúmenes a diferentes imprentas cuando se querían publicar en un mismo año. Lorenzo Ruiz Fidalgo la cita como Comentaria in Galenum de facultatibus naturalibus y no le asigna impresor. Ibídem, p. 885. A. H. P. Sa. P. N. Leg. 4625. 9-V-1580. Fols. 1735-1736. Ma MARSÁ, La imprenta en los Siglos de Oro (1520-1700). Madrid, 2001, p. 18.

135 Biblia Sacra cum duplici translatione et scholiis Francisci Vatabli. 1584. L. RUIZ FIDALGO, Op. cit., III, p. 962-964.

136 In librum duodecim prophetarum comentarii. Ibidem, p. 1038.

137 Dialogus de triplici bono et vera hominis nobilitate quie Philemon inscribitur. 1588. Ibidem, p. 1071.

138 De Deo eiusque operibus. Commentaria in primam partem S. Thomae. 1590. Ibidem, p. 1113-1114. 


\begin{tabular}{|c|c|c|c|c|}
\hline $\begin{array}{l}\text { Convento Nra. } \\
\text { Sra. de Loreto } \\
\text { (Sal.) }\end{array}$ & Misales & $\begin{array}{l}\text { Juan Fernández y } \\
\text { Juan Pulman }\end{array}$ & 1000 & 1589 \\
\hline $\begin{array}{l}\text { Fray Luis de } \\
\text { Granada }\end{array}$ & Catecismo & Julio de Junta & 1600 & 1589 \\
\hline $\begin{array}{l}\text { Lorenzo Osorio } \\
\text { Barba (canónigo) }\end{array}$ & Pina de rosas ${ }^{139}$ & Julio de Junta & 1000 & 1589 \\
\hline $\begin{array}{l}\text { Ldo. Diego de la } \\
\text { Cantera }\end{array}$ & $\begin{array}{l}\text { Questiones } \\
\text { criminales }^{140}\end{array}$ & Cornelio Bonart & 1000 & 1589 \\
\hline $\begin{array}{l}\text { Fray Pedro de } \\
\text { Aragón } \\
\text { (O. E. S. A.) }\end{array}$ & $\begin{array}{l}2^{\circ} \text { Tomo de la Secunda } \\
\text { secundae (Sto } \\
\text { Tomás) }{ }^{141}\end{array}$ & Julio de Junta & 1025 & 1589 \\
\hline $\begin{array}{l}\text { Ldo Juan Yánez } \\
\text { de Parladoiro }\end{array}$ & $\begin{array}{l}\text { Rerum quotidianarum } \\
\text { (secunda parts) }{ }^{142}\end{array}$ & $\begin{array}{l}\text { Juan y Andrés } \\
\text { Renaut }\end{array}$ & 1000 & 1590 \\
\hline $\begin{array}{l}\text { Fray Pedro } \\
\text { Cañedo (O. F. } \\
\text { M.) }\end{array}$ & $\begin{array}{l}\text { Compendium de } \\
\text { Sacramentis }{ }^{143}\end{array}$ & $\begin{array}{l}\text { Andrés Arnao } \\
\text { (Renaut) }\end{array}$ & 1500 & 1591 \\
\hline $\begin{array}{l}\text { Miguel de } \\
\text { Palacios } \\
\text { (canónigo) }\end{array}$ & Profetas menores ${ }^{144}$ & $\begin{array}{l}\text { Antonio, Juan y } \\
\text { Andrés Arnao } \\
\text { (Renaut) }\end{array}$ & 500 & 1591 \\
\hline
\end{tabular}

139 Piña de rosas citadas por graves y sanctos autores theólogos y Canonistas. Guillermo Foquel. Ibídem, p. 1091-1092.

140 Questiones criminales tangentem iudicem, accusatirem, reum, probationem, punitionemquem delictorum. Ibidem, p. 1078.

141 In secumdam secundae divi Thomae commentaria: De iustitia et iure. Guillermo Foquel. Ibidem, p. 11031104.

142 Rerum quotidianarum liber alter. 1591. Ibidem, p. 1191.

143 1592. Juan y Andrés Arnao. Ibidem, 1135-1136.

144 Explanationes in duodecim prophetas menores. 1593. Ibidem, p. 1158. 